\title{
Radiation-Induced Demagnetization of Nd-Fe-B Permanent Magnets
}

\author{
J. Alderman and P.K. Job \\ APS Operations Division \\ Advanced Photon Source \\ Argonne National Laboratory \\ R.C. Martin, C.M. Simmons, and G.D. Owen \\ Californium User Facility for Neutron Science \\ Chemical Technology Division \\ Oak Ridge National Laboratory \\ J. Puhl \\ Ionizing Radiation Division \\ National Institute of Standards and Technology
}

November 2000

work sponsored by

U.S. DEPARTMENT OF ENERGY

Office of Energy Research 


\title{
Radiation-Induced Demagnetization of Nd-Fe-B Permanent Magnets
}

J. Alderman and P.K. Job

APS Operations Division

Advanced Photon Source

Argonne National Laboratory

R.C. Martin, C.M. Simmons, and G. D. Owen

Californium User Facility for Neutron Science

Chemical Technology Division

Oak Ridge National Laboratory

J. Puhl

Ionizing Radiation Division

National Institute of Standards and Technology

November 2000

\section{Table of Contents}

\author{
Introduction \\ Radiation-Induced Demagnetization of Permanent Magnets \\ Resources Required for Irradiation \\ $\gamma$-ray Irradiation \\ Results and Analysis of $\gamma$-ray Irradiation \\ X-ray Irradiation \\ Results and Analysis of X-ray Irradiation \\ Neutron Irradiation \\ Results and Analysis of Neutron Irradiation \\ Summary and Conclusions \\ Acknowledgements \\ References \\ Tables and Figures
}




\section{Introduction}

The Advanced Photon Source (APS), as well as other third-generation synchrotron light sources, uses permanent magnets in the insertion devices to produce x-rays for scientific research [1,2]. When placed in a high-energy storage ring, these permanent magnets are subjected to irradiation from synchrotron radiation, high-energy bremsstrahlung, and bremsstrahlung-produced neutrons. Previous investigations have exhibited varying degrees of degradation in the intensity of magnetization of these magnets [3] due to irradiation from electron beams $[4,5,6,7,8],{ }^{60} \mathrm{Co} \gamma$-rays $[5,7,9]$, and high-energy neutrons $[3,10,11]$. The APS specifically uses Nd-Fe-B permanent magnets in the insertion devices [2]. Although no detectable radiation-induced demagnetization has been observed in the APS insertion devices so far [12], partial demagnetization has been observed in at least one insertion device at the European Synchrotron Radiation Facility (ESRF) [4,6], where $\mathrm{Nd}-\mathrm{Fe}-\mathrm{B}$ permanent magnets are also used.

A growing concern for the APS insertion devices as well as the insertion devices of nextgeneration light sources, such as free-electron lasers (FELs) [13,14] where permanent magnets will also be used, resulted from the partial demagnetization observed at the ESRF. Greater potential for irradiation of the Nd-Fe-B permanent magnets used in the APS insertion devices results from the close proximity of the electron beam to the magnets themselves. During normal operation the magnets will be as close as 3-5 mm from the electron beam. This close proximity increases the potential of magnet irradiation from synchrotron radiation and high-energy bremsstrahlung. Typically the APS insertion devices receive a photon dose of approximately 1 Mrad during every APS run, which generally lasts two months with approximately 100 Amp-h of beam current [15]. This results in an absorbed photon dose of approximately 7 Mrad per year, or approximately $130 \mathrm{Mrad}$ after 20 years of operation, which is the desired lifespan of the APS insertion devices. At this point in time no measurements have been done to determine the neutron dose received by the insertion devices during a normal APS run. However the neutron dose is expected to be much lower than the combined photon dose of x-rays and $\gamma$-rays because the photoneutron production in an electromagnetic shower is minimal [16]. Calculations performed at the APS of the neutron flux present as a result of the entire 100 $\mathrm{mA}$ of stored beam loss on a beamline element revealed an instantaneous neutron pulse of $2 \times 10^{8}$ neutrons. Similar calculations for the neutron flux produced during a continuous injection loss of 84 watts at the design performance goal revealed a flux of $1.9 \times 10^{11}$ neutrons/second.

Next-generation light sources will by far exceed the third-generation sources in terms of brightness, coherence, beam power, and energy [14]. The brightness of radiation produced in such sources is expected to be several orders of magnitude higher than current, third-generation sources [17]. This increase in brightness from the enhanced synchrotron radiation would result in a greater absorbed dose to the insertion devices from synchrotron radiation scattering.

Bremsstrahlung radiation will also be several orders of magnitude higher for future light sources and is expected to increase the absorbed doses to the insertion devices. The high 
power output of these next-generation sources is expected to degrade the vacuum of the long straight sections many orders of magnitude. This vacuum degradation due to radiation desorption will increase the absorbed dose received by the insertion devices due to increased gas bremsstrahlung, as gas bremsstrahlung from the straight section increases linearly with pressure [18]. The longer straight sections of approximately 50 meters, in the case of the linear free-electron lasers, will also account for an increase in bremsstrahlung. Larger beam bunches required for the single-pass operation of linear accelerators used in next-generation sources again will contribute to an increase in bremsstrahlung, as measurements at the APS showed that bremsstrahlung increases as the square of the transverse bunch profiles [18]. Smaller vacuum chambers proposed for use in the next-generation sources may also contribute to the absorbed doses due to bremsstrahlung depending on the beam location inside the chamber. Neutrons, resulting from bremsstrahlung interactions with high- $Z$ materials in the beamlines [19], will also factor into the absorbed doses received by the insertion devices of current, as well as next-generation sources.

\section{Radiation-Induced Demagnetization of Permanent Magnets}

Previous investigations into the radiation-induced demagnetization of permanent magnets similar to those used in the APS insertion devices produced varying results. Okuda et al. [5] performed a $\gamma$-ray irradiation of $\mathrm{Nd}-\mathrm{Fe}-\mathrm{B}$ sample magnets in a ${ }^{60} \mathrm{Co}$ irradiation facility at the Institute of Scientific and Industrial Research (ISIR) at Osaka University. The sample magnets were irradiated in the $\gamma$-ray source at a temperature of $20^{\circ} \mathrm{C}$ for a period of 459 hours [5]. The total absorbed dose to the magnets was determined using Celium dosimeters. The magnetic flux loss for the ${ }^{60} \mathrm{Co} \gamma$-ray irradiation of $\mathrm{Nd}-\mathrm{Fe}-\mathrm{B}$ permanent magnets at an absorbed dose rate of $610 \mathrm{krad} / \mathrm{h}$ to an absorbed dose of $280 \mathrm{Mrad}$ was below $0.5 \%$ [5].

Results cited in Luna et al. [7] stated no remanence loss for the $\gamma$-ray irradiation of $\mathrm{Nd}$ Fe-B permanent magnets. A sample of $\mathrm{Nd}_{2} \mathrm{Fe}_{14} \mathrm{~B}$ alloy was placed in a ${ }^{60} \mathrm{Co}$ tank and irradiated to a maximum dose of $69 \mathrm{Mrad}$. "Initial" and "final" remanence readings were measured using a hand-held Hall probe gauss meter [7]. Boockmann et al. [9] measured the effect of $\gamma$-ray irradiation from a ${ }^{60} \mathrm{Co}$ source on the magnetic properties of sintered $(\mathrm{Nd}, \mathrm{Dy})_{15} \mathrm{Fe}_{77} \mathrm{~B}_{8}$ magnets. Up to an accumulated dose of about 50 Mrad neither the remanent polarization nor the intrinsic coercivity were significantly affected. The remanent polarization of every magnet was measured along with the demagnetization curve [9].

Numerous studies involving the irradiation effects of direct electron beams on Nd-Fe-B permanent magnet samples have been conducted. Direct electron beam irradiation yields useful results for situations when the particle beam is lost directly on the magnet. If the particle beam, or electron beam were missteered, or lost, directly on the magnet, an electromagnetic shower would be produced. The subsequent irradiation of the magnet would be the direct result of the electromagnetic shower produced, consisting of $\gamma$-rays, electrons, positrons, and neutrons. Nd-Fe-B sample magnets were irradiated to an electron dose of $260 \mathrm{Mrad}$ at the ISIR at Osaka University [5,20]. The magnetic flux of 
the sample magnets was measured using an open coil, evaluating the total magnetic flux of the sample [5]. The flux loss at an absorbed dose of $260 \mathrm{Mrad}$ was found to be approximately $9 \%$ [5,12], with an increase in flux loss for higher doses [5].

A similar study using an $82-\mathrm{MeV}$ electron beam was performed at the linear accelerator of Lawrence Livermore National Laboratory [7]. Magnetic measurements compared the open circuit remanence of each sample magnet before and after irradiation using an integrated fluxmeter [7]. Two sample magnets were irradiated with a direct 82-MeV electron beam to a total dose of $36 \mathrm{krad}$ [7]. The $\mathrm{Nd}_{2} \mathrm{Fe}_{14} \mathrm{~B}$ sample showed a $1.5 \%$ remanence loss that was determined statistically significant. Exposure to bremsstrahlung radiation from an $85-\mathrm{MeV}$ electron beam to a total dose of $450 \mathrm{Mrad}$ resulted in a $14 \%$ remanence loss [7,12]. A second $\mathrm{Nd}-\mathrm{Fe}-\mathrm{B}$ sample, from a different manufacturer, displayed a $2 \%$ remanence loss after electron-beam irradiation to a total dose of 1370 Mrad, suggesting that magnet composition from different manufacturing processes may have an effect on the rate of remanence loss [7,12].

The partial demagnetization of the two insertion devices at the ESRF, from missteering of the electron beam onto the vacuum chamber wall of the device, resulted in severe degradation of magnetic properties [8]. The estimated absorbed dose to one of the damaged devices was 6.7 Mrad to the first upper magnet, and 5.1 Mrad to the first lower magnet [12]. This dose resulted in a peak magnetic field loss at the upstream end of the device of approximately 8\% [12], with demagnetization over one third of the length of the device [6]. This observed demagnetization at the ESRF prompted a subsequent irradiation program to test the sensitivity of various types of permanent magnets to electron beam irradiation. Three different types of Nd-Fe-B samples, along with two Samarium-Cobalt samples, were irradiated with a 180-MeV electron beam from the ESRF linear accelerator $[4,8]$. The samples were irradiated for one hour to an estimated dose of 70 Mrad [4,8]. All of the Nd-Fe-B samples showed partial demagnetization, with greater demagnetization observed in the samples with higher remanence and lower coercivity [4].

The ESRF partial demagnetization also prompted a similar study at HASYLAB that focused on possible radiation damage to permanent magnet insertion devices during routine operation of the storage ring. In this case the permanent magnets had been subjected to a realistic irradiation environment within the storage ring, where the particle beam usually is not lost directly on the magnets. This particular study focused primarily on the x-ray irradiation of the permanent magnets over time, rather than irradiation from the electromagnetic shower produced from direct electron beam irradiation. However a pure $\mathrm{X}$-ray irradiation was not specifically conducted in this study. Magnetic measurements on an X-ray wiggler at HASYLAB were repeated in 1994 and compared to measurements taken during acceptance tests done prior to installation in 1991 [8]. The total dose was measured on the surface of the upstream end of the magnetic structure at different horizontal positions using thermoluminescence dosimeters [8]. The total estimated dose during the two-year period, corresponding to a total stored current of 214 Amp-hours, was 7.2 Mrad directly above the beam, and 3.3 Mrad and $12 \mathrm{Mrad}$ at positions displaced horizontally by $40 \mathrm{~mm}[8,12]$. Extensive magnetic measurements 
included field mapping using Hall probes, field integral measurement using short coils and Hall probes, determination of normal and skew integrated multipole components, as well as gap dependence of field integrals [8]. As a result of these extensive measurement procedures, it was determined that radiation-induced effects could not be detected within the accuracy of the measurements.

A few investigations have been done to determine the effects of neutron irradiation on $\mathrm{Nd}-\mathrm{Fe}-\mathrm{B}$ magnetic properties due to the relatively recent development of $\mathrm{Nd}-\mathrm{Fe}-\mathrm{B}$ permanent magnet materials in the early 1980's [21]. Cost et al. [10] performed a neutron irradiation of Nd-Fe-B permanent magnets from two different manufacturers in the Omega West reactor at Los Alamos National Laboratory. Sample Nd-Fe-B permanent magnets were irradiated with fast neutrons to a fluence of $5.0 \times 10^{16} \mathrm{n} / \mathrm{cm}^{2}$ at a temperature of $153^{\circ} \mathrm{C}$, and to a fluence of $6.1 \times 10^{16} \mathrm{n} / \mathrm{cm}^{2}$ at a temperature of $77^{\circ} \mathrm{C}[10]$. The thermal neutron flux was attenuated by shielding the reactor port with cadmium, resulting in an estimated fast neutron flux of $4 \times 10^{12} \mathrm{n} / \mathrm{cm}^{2} \mathrm{~s}$ [10]. At specified times during the irradiation the magnets were removed from the reactor to measure the open-circuit remanence at room temperature using a 500-turn coil and a high-speed digital voltmeter [10]. Significant losses of magnetization were observed immediately with irradiation. At $77^{\circ} \mathrm{C}$ the initial loss of remanence was approximately $5 \%$ at a fluence level of $10^{15} \mathrm{n} / \mathrm{cm}^{2}$. At $153^{\circ} \mathrm{C}$ the initial loss of remanence was $10 \%$ at a fluence level of $10^{15} \mathrm{n} / \mathrm{cm}^{2}$ [10]. Only slight differences in the rate of demagnetization at a given temperature were observed for samples from two different manufacturers, however large differences were observed for the two different irradiation temperatures [10].

Brown et al. [3] extended the previous study to include a number of commercially available Nd-Fe-B permanent magnet materials. Sample Nd-Fe-B permanent magnets from five different vendors were irradiated in the Omega West reactor at Los Alamos National Laboratory to a fast neutron flux of $4 \times 10^{12} \mathrm{n} / \mathrm{cm}^{2} \mathrm{~s}$ at a temperature of $77^{\circ} \mathrm{C}$. Magnetic measurements were similar to the previous study. To allow for meaningful comparisons of the different materials, all of the Nd-Fe-B permanent magnet samples had the same length-to-diameter ratio [3]. Results showed that fast neutron irradiation of NdFe-B permanent magnets from different manufacturers exhibited different rates of radiation-induced demagnetization [3]. The study also found that resistance to radiationinduced demagnetization could be improved by the substitution of Dy or Tb for $\mathrm{Nd}$ [3].

Another investigation by Brown et al. [11] studied the neutron irradiation effects on NdFe-B permanent magnets made from melt-spun ribbons as compared to the effects on sintered Nd-Fe-B permanent magnets as previously discussed. Irradiation of the meltspun ribbon based sample Nd-Fe-B magnets was carried out at the Omega West reactor at Los Alamos National Laboratory under experimental conditions similar to those discussed for previous investigations. Measurements of the open-circuit remanence at various times during the irradiation displayed a $1.5 \%$ decrease in remanence after onehour of irradiation, or a dose of $1.4 \times 10^{16} \mathrm{n} / \mathrm{cm}^{2}$, as compared to a $4.6 \%$ drop in remanence for the best sintered Nd-Fe-B sample permanent magnet [11]. After 5.3 hours of irradiation the remanence only dropped by $3 \%$ for the melt-spun ribbon based sample $\mathrm{Nd}-\mathrm{Fe}-\mathrm{B}$ magnets [11]. The study concluded that Nd-Fe-B permanent magnets made 
from melt-spun ribbons are less sensitive to neutron irradiation than sintered Nd-Fe-B permanent magnets, but they are somewhat more sensitive than Sm-Co permanent magnets [11].

This investigation extended beyond the scope of previous investigations in that it provided the first complete study of the radiation-induced demagnetization of $\mathrm{Nd}-\mathrm{Fe}-\mathrm{B}$ sample magnets from all types of radiation that the permanent magnets are subjected to under normal operating conditions within synchrotron radiation sources. The specific NdFe-B sample used in all of the irradiations in this study was a typical commercially available material known as $\mathrm{N} 38 \mathrm{H}$. This investigation used small $\mathrm{Nd}-\mathrm{Fe}-\mathrm{B} \mathrm{N} 38 \mathrm{H}$ samples that are identical to those specifically used in the insertion devices in synchrotron radiation sources.

Most of the previous investigations concentrated on irradiation with either photons or neutrons, while this study considered the effects of x-rays, $\gamma$-rays, and neutrons separately. This study also differentiated between the effects of fast-neutron and thermalneutron irradiation. Previous $\gamma$-ray irradiations of $\mathrm{Nd}-\mathrm{Fe}-\mathrm{B}$ sample magnets using a ${ }^{60} \mathrm{Co}$ pure $\gamma$-ray source studied the systematic irradiation effects up to a maximum absorbed dose of $280 \mathrm{Mrad}$. In the present investigation ${ }^{60} \mathrm{Co}$ irradiation went as far as $700 \mathrm{Mrad}$. Prior to this investigation a pure $\mathrm{x}$-ray irradiation of the $\mathrm{Nd}-\mathrm{Fe}-\mathrm{B}$ sample magnets had never been performed. Numerous studies involving the irradiation effects of direct electron beams on $\mathrm{Nd}-\mathrm{Fe}-\mathrm{B}$ permanent magnet samples have been conducted. However, direct electron beam irradiation yields results for situations when the particle beam is lost directly on the magnet. Under normal operating conditions, and with beam position monitors and feedback systems this situation is a remote possibility. Therefore a pure $\mathrm{x}$ ray irradiation is a more realistic approach in understanding the radiation-induced demagnetization of the $\mathrm{Nd}-\mathrm{Fe}-\mathrm{B}$ sample magnets under routine storage ring conditions.

Specific fast-neutron irradiation as well as thermal-neutron irradiation also differentiated this study from previous work. Only fast neutrons were considered in previous investigations. This work also considered temperature control during the neutron irradiations while other investigations overlooked it. Finally, the neutron irradiations were the first nonreactor-based irradiations, allowing for pure and controlled conditions similar to the routine storage ring conditions that the sample magnets are subjected to in synchrotron radiation sources.

\section{Resources Required for Irradiation}

The Nd-Fe-B permanent magnet samples used for this investigation were procured from Dexter Corporation, Magnetic Technologies, of Elk Grove Village, Illinois. The specific $\mathrm{Nd}-\mathrm{Fe}-\mathrm{B}$ material used in the magnets is a typical commercially available material known as $\mathrm{N} 38 \mathrm{H}$. The sample magnet dimensions were approximately $5 \mathrm{~cm} \times 4.75 \mathrm{~cm} \times 0.7 \mathrm{~cm}$. All of the sample magnets were plated with a thin coating of nickel to reduce the brittleness of the Nd-Fe-B magnetic material. 
Irradiation of the Nd-Fe-B permanent magnets required resources encompassed in three distinct disciplines including high-dose dosimetry, magnetic measurements, and temperature measurements. In order to measure x-ray irradiation doses greater than $10^{6}$ rad received by the sample permanent magnets, a reliable photon high-dose dosimetry technique was required, which was not readily available at the APS at the time. Through a collaboration with NIST, a technique using radiachromic films was considered, tested, and calibrated at the APS [15]. Radiachromic films are nylon-based aminotriphenyl methane dye derivatives $[22,23]$. Upon exposure to ultraviolet light or ionizing radiation, the films undergo radiation-induced coloration by photoionization [22,24]. The radiationinduced photochemical reaction is displayed in Figure 1. This reaction results in a change from a clear or colorless state to a deep blue-colored state, which occurs gradually as a direct function of the radiation exposure received $[22,25]$. The change in the color intensity, or optical density, is measured using an optical reader, or a simple spectrophotometer.

The radiachromic films used for the magnet irradiation were FWT-60 films procured from Far West Technology of Goleta, California. These films have a linear response to ionizing radiation over a dose range of approximately $0.1 \mathrm{Mrad}$ to $10 \mathrm{Mrad}[22,25,26]$. The films also have an equivalent response to $\mathrm{x}$-rays, $\gamma$-rays, and electrons from ultraviolet energies up to approximately $1 \mathrm{MeV}[27,28,29]$. Radiachromic films display a constant response for exposures in air and vacuum, as well as in the presence of ozone $[22,23,30]$. Absorbed doses measured are relatively insensitive up to an ambient temperature of $50^{\circ} \mathrm{C}[25]$.

Through a collaboration, the radiachromic films were calibrated at the NIST standard gamma irradiation facility, GC232. The irradiation dose rate was $936.3 \mathrm{krad} / \mathrm{hr}$, and the films were calibrated up to 10 Mrad. During the calibration the relative humidity was maintained at $44 \%$. The individual films were placed inside paper detector envelopes and then sealed in aluminized Mylar pouches to protect them from ultraviolet exposure. For the calibration irradiation, the pouches were placed between two 5.0-mm-thick blocks of polystyrene to simulate tissue absorption. They were then placed upright on a polystyrene pedestal. The temperature during irradiation was controlled with forced air blown down on the samples and measured every sixty seconds. The calibration curve for the FWT-60 radiachromic films is given in Figure 2.

Measurement of the degree of degradation in the intensity of the magnetization of the NdFe-B permanent magnets as a result of irradiation required a magnetic measurement system. This system was comprised of a Helmholtz coil and a fluxmeter. An eight-inch Helmholtz coil, Model HC-8, and a Model 2130 fluxmeter were procured from Magnetic Instrumentation Inc., of Indianapolis, Indiana. Helmholtz coils were found to be ideal for the measurement of rare earth (samarium cobalt, neodymium) and hard ferrite permanent magnets [31,32]. The Helmholtz coil measures the magnet sample as a single magnetic moment provided that the magnet sample's longest dimension is less than one third of the diameter of the coil [31,32]. By definition the magnetic moment per unit volume is the intrinsic magnetization of the sample. When the Helmholtz coil is used in conjunction with the Model 2130 fluxmeter, and given the volume of the permanent magnet sample, 
the intrinsic open circuit operating $B$, or measure of the intrinsic remnant induction in a magnet sample is given in units of Bdi-Tesla [31]. The units of Bdi-Tesla are based on coil and magnet parameters; therefore, the Helmholtz coil constant and the coil resistance as well as the volume of the magnet sample must be known and entered into the coil parameter and magnet volume menus of the fluxmeter prior to magnet measurement. A list of the sample magnet and coil parameters for the magnetic measurements used in conjunction with irradiation of the Nd-Fe-B sample magnets is provided in Table 1.

To determine the precision of the fluxmeter in terms of the measurement of the intrinsic remnant induction of the sample magnets, 100 measurements were taken for each of four sample magnets. The standard deviation was then calculated for each of the four data sets. In all cases the standard deviation was approximately $2 \times 10^{-3}$. Assuming a normal distribution, $99 \%$ of the sample measurements will fall within three standard deviations $(3 \sigma)$ of the sample mean. Using $2 \times 10^{-3}$ as the average standard deviation $(\sigma)$, three standard deviations give a range of \pm 0.006 . Therefore, measured changes in the intrinsic remnant induction greater than 0.006 will be detected using this fluxmeter.

Two aspects of the irradiation required temperature control and measurement, namely the radiachromic films and the sample magnets themselves. As stated before, the radiachromic films have no temperature dependence up to $50^{\circ} \mathrm{C}$ [2]. Because the films were placed directly on the sample magnets during the $\mathrm{x}$-ray irradiation, the sample magnets had to be kept below $50^{\circ} \mathrm{C}$.

The main disadvantage of Nd-Fe-B permanent magnets is their low Curie temperature. This leads to increased sensitivity to thermal demagnetization and limits their maximum temperature range $[8,33]$. The maximum use temperature for commercially available permanent magnets is typically less than $120^{\circ} \mathrm{C}$ [34]. The APS insertion device permanent magnets were all stabilized before the assembly of the devices so that temperatures up to $60^{\circ} \mathrm{C}$ would not cause any temperature-induced demagnetization [12]. In order to hinder temperature-induced demagnetization so as not to interfere with the radiation-induced demagnetization results, the temperature had to be kept below $60^{\circ} \mathrm{C}$ for the $\gamma$-ray irradiation and below $50^{\circ} \mathrm{C}$ for the $\mathrm{x}$-ray irradiation due to the temperature constraint of the radiachromic films.

Viewdac (Revision 2.20), a control program from Keithley Instruments, Inc., was installed on a PC for the sole purpose of providing a temperature measurement system to use during the x-ray irradiation of the sample permanent magnets. The software was loaded and a specific program was written that allowed six thermocouples to monitor six separate temperatures during the irradiation. The thermocouples were CHROMEGA $^{\mathrm{TM}} /$ ALOMEGA $^{\mathrm{TM}}$, 0.10-inch-diameter, 36-inch-long Teflon-insulted thermocouples procured from OMEGA Engineering, Inc. of Stamford, CT. This temperature measurement system encompassed the resources needed for measurements that were required for temperature control during the $\mathrm{x}$-ray irradiation of the sample magnets. The temperature during the $\gamma$-ray irradiation was held constant at $30^{\circ} \mathrm{C}$ by forced-air cooling of the irradiation setup with house air at $20 \mathrm{psi}$; therefore temperatureinduced demagnetization of the sample permanent magnets was not an issue. 
Following the irradiation, statistical inference and a pooled t-test [35] were used to determine if a difference existed between the intrinsic remnant induction averages taken prior to irradiation and the average measurements taken after irradiation for very small percent differences. When large percent differences were observed, these methods were not necessary. Because of the small sample size, $n=5$ readings taken for each magnet, the populations were assumed to be normally distributed, and the hypothesis test was based on confidence intervals and the $t$-distribution [35]. The difference in means, $\mu_{1}=$ preirradiation mean and $\mu_{2}=$ postirradiation mean, was determined by combining the two sample variances, $\mathrm{s}_{1}{ }^{2}$ and $\mathrm{s}_{2}{ }^{2}$, to form an estimator of the variance of the normal distribution $\sigma^{2}$. This estimator, called a pooled estimator of $\sigma^{2}$, is denoted by $\mathrm{S}_{\mathrm{p}}{ }^{2}$.

A hypothesis test was formed using a null hypothesis $\mathrm{H}_{\mathrm{o}}$ and an alternative hypothesis $\mathrm{H}_{1}$. In this case we wished to test whether or not the means were equal, or $\mathrm{H}_{\mathrm{o}}: \mu_{1}=\mu_{2}$ and $\mathrm{H}_{1}: \mu_{1} \neq \mu_{2}$. The purpose of the test is to use a test statistic $t_{\mathrm{o}}$ that will support either the acceptance or rejection of the null hypothesis $H_{0}$. The pooled estimator of $\sigma^{2}$ was found using sample sizes $\mathrm{n}_{1}=\mathrm{n}_{2}=5, \mathrm{~s}_{1}{ }^{2}$, and $\mathrm{s}_{2}{ }^{2}$ set equal to the sample variances, and the following equation:

$$
\mathrm{S}_{\mathrm{p}}^{2}=\left[\left(\mathrm{n}_{1}-1\right)^{*} \mathrm{~s}_{1}^{2}+\left[\left(\mathrm{n}_{2}-1\right)^{*} \mathrm{~s}_{2}^{2}\right] /\left[\mathrm{n}_{1}+\mathrm{n}_{2}-2\right]\right.
$$

The confidence interval was chosen, in this case the $99 \%$ confidence interval with $\alpha=$ 0.01 . This was used to determine the critical value $t_{\mathrm{cr}}$ that, when compared to the test statistic $t_{\mathrm{o}}$, supports either the acceptance or rejection of the null hypothesis. Values for $t_{\mathrm{cr}}$ are taken from statistical tables listing the percentage points of the $t$-distribution [35].

The test statistic was computed using the sample averages of the intrinsic remnant induction, the pooled estimator, sample sizes $\mathrm{n}_{1}$ and $\mathrm{n}_{2}$, and the following equation:

$$
t_{\mathrm{o}}=\left[\mu_{1}-\mu_{2}-0\right] /\left[\mathrm{S}_{\mathrm{p}} * \operatorname{sqrt}\left(\left(1 / \mathrm{n}_{1}\right)+\left(1 / \mathrm{n}_{2}\right)\right)\right]
$$

The test statistic has a $t$-distribution with $\left(\mathrm{n}_{1}+\mathrm{n}_{2}-2\right)$ degrees of freedom under $\mathrm{H}_{\mathrm{o}}: \mu_{1}=$ $\mu_{2}$. If $t_{\mathrm{o}}>t_{\mathrm{cr}}$ or if $t_{\mathrm{o}}<-t_{\mathrm{cr}}$, the null hypothesis $\mathrm{H}_{\mathrm{o}}$ is rejected, providing evidence at the 0.01 significance level, or the $99 \%$ confidence interval, that the two means differ.

\section{$\gamma$-ray Irradiation}

A systematic $\gamma$-ray irradiation of the $\mathrm{Nd}-\mathrm{Fe}-\mathrm{B}$ permanent magnets was done through a collaboration with the NIST Ionizing Radiation Division. The NIST standard gamma irradiation facility, Gammacell® GC232, a Cobalt-60 irradiation facility, was used to irradiate the magnets. Four sample magnets along with two control magnets were sent back and forth to NIST for a total of six irradiations. For each of the first five irradiations, the four sample magnets were irradiated in absorbed dose increments of $100 \mathrm{Mrad}$. The magnets were irradiated in an absorbed dose increment of 200 Mrad for the sixth 
irradiation. The six $\gamma$-ray irradiations resulted in a total absorbed dose to the sample magnets of approximately 700 Mrad.

As stated previously, the temperature during the $\gamma$-ray irradiation was held constant within the irradiation facility, which helped to control any temperature-induced demagnetization of the sample magnets. The temperature was kept at approximately $30^{\circ} \mathrm{C}$ with air blown down onto the samples at 20 psi. This was well below the $60^{\circ} \mathrm{C}$ temperature requirement for the magnets. The high-dose dosimetry component of the irradiation was also satisfied by the NIST irradiation facility through the calibrated Gammacell@. Calibrated radiachromic films, in pouches, were placed between the magnets for a three-hour irradiation to verify an absorbed dose rate of $708.6 \mathrm{krad} / \mathrm{hr}$.

Prior to sending the magnets to NIST for irradiation, intrinsic remnant induction readings were taken at the APS for each magnet. Four sample magnets, along with two control magnets were read using the magnetic measurement system previously described. Five measurements of the intrinsic remnant induction were taken for each sample magnet, as well as for the two control magnets. The average of these measurements served as initial readings to be compared to measurements taken after irradiation. All six magnets were wrapped in cardboard, approximately 3-mm thick, to reinforce safe handling. The four sample magnets were then stacked upright and wrapped in another layer of cardboard. They were then shipped along with the two control magnets to NIST for irradiation.

The magnet configuration described above was left in place during irradiation of the four sample magnets. Once the stacked arrangement of magnets was placed inside the center of the irradiation chamber, two rings of cardboard were fit onto each end to fill the chamber diameter and keep the magnets centered and upright. The Gammacell@ itself consists of an annular source permanently enclosed within lead shielding, a cylindrical drawer, and a drive mechanism to move the drawer up and down along the vertical source center line [36]. A chamber in the drawer is used to carry the samples from outside the shield to inside the source for irradiation. The ${ }^{60} \mathrm{Co}$ source cage contains 48 "pencil" source positions. These tubular "pencil" sources each contain seven ${ }^{60}$ Co slugs that are completely sealed in by welded end caps [36]. They are placed in an annular formation on an 8.32-inch pitch circle diameter around the source cage. A diagram of the source cage and arrangement of the "pencil" sources is shown in Figure 3.

After irradiation the sample magnets were packaged along with the control magnets and sent back to the APS. Upon arrival, five measurements of the intrinsic remnant induction were taken for each sample magnet as well as the two control magnets. An average was taken for each set of measurements. These "final" averages were then compared to the "initial" averages taken prior to irradiation, using the pooled t-test previously described, to determine if any measurable radiation-induced demagnetization had occurred.

Following statistical analysis of the "initial" and "final" readings, "initial" intrinsic remnant induction readings were again taken at the APS for each of the four sample magnets as well as the two control magnets. The magnets were then sent back to NIST for the next irradiation in the cycle. This process continued for a total of six irradiations 
resulting in a total absorbed dose to the sample permanent magnets of approximately $7 \times 10^{8} \mathrm{rad}$.

\section{Results and Analysis of $\boldsymbol{\gamma}$-ray Irradiation}

Intrinsic remnant induction measurements for each magnet prior to $\gamma$-ray irradiation compared to measurements following irradiation revealed small but not insignificant levels of variation. Table 2 shows the deterioration of the intrinsic remnant induction as a percent change for each irradiation step as compared to the percent change observed in the unirradiated control magnets. Figure 4 shows the same results, but provides a graphical format. From the tables, a $0.1 \%-0.2 \%$ variation occurs at each irradiation step, but is not a cumulative effect. Because high accuracy is required in the magnetic fields of insertion devices, changes of this magnitude may cause diminished performance. Typically a $0.5 \%$ change in the magnetic field of insertion devices cannot be tolerated [5]. However, the $0.1 \%-0.2 \%$ level of variation observed in this case is right at the edge of the precision capabilities of the fluxmeter and is observed in the control magnets as well. Therefore, the variations are not statistically significant and may be attributable to the precision level of the instrument rather than radiation-induced demagnetization.

The change at each step in the $\gamma$-ray irradiation process was never more than $0.1 \%-0.2 \%$ as compared to the measurements taken prior to the first irradiation. In other words, there was not a cumulative effect. If the change in the intrinsic remnant induction were the result of radiation-induced demagnetization, greater changes with increasing irradiation levels would be expected. The precision level of the instrument accounting for the observed variations may explain the absence of this effect, but it may also be due to the "stepwise" irradiation procedure. An annealing effect may have been taking place between irradiations, resulting in a $0.1 \%-0.2 \%$ total change after each irradiation rather than a $0.1 \%-0.2 \%$ change for each irradiation added cumulatively over all six irradiations.

The pooled $t$-test, described previously, was used to compare the preirradiation means of the intrinsic remnant induction measurements to the means found at each step in the irradiation process. Almost every comparison done using the test revealed evidence of differences between the means. However, the $0.1 \%-0.2 \%$ level of variation is right at the edge of the precision capabilities of the fluxmeter, so although there may be differences between the means, the variations may be attributable to the precision level of the instrument rather than radiation-induced demagnetization.

The results of this study agree with previous work [5,7,9] that shows the effect of $\gamma$-ray irradiation on the radiation-induced demagnetization of $\mathrm{Nd}-\mathrm{Fe}-\mathrm{B}$ permanent magnets is small, but not insignificant if the changes can be determined statistically significant. However, due to the precision capabilities of the fluxmeter, the $0.1 \%-0.2 \%$ level of variation observed in this study cannot be attributed to radiation-induced demagnetization of the sample magnets. In relation to previous studies, this investigation went much further in terms of the range of absorbed doses to the irradiated sample magnets. Previous $\gamma$-ray irradiations of $\mathrm{Nd}-\mathrm{Fe}-\mathrm{B}$ sample magnets using a ${ }^{60} \mathrm{Co}$ source only went up to a 
maximum absorbed dose of less than $300 \mathrm{Mrad}[5,7,9]$. This study found no measurable radiation-induced demagnetization up to a $\gamma$-ray irradiation dose of $700 \mathrm{Mrad}$.

\section{X-ray Irradiation}

The APS beamline $9 \mathrm{BM}$ was used for the systematic $\mathrm{x}$-ray irradiation of the Nd-Fe-B sample magnets. The sample magnets were placed in a specially designed holder inside the experimental hutch and irradiated with an x-ray spectrum with a peak energy of approximately $40 \mathrm{keV}$ from the bending magnet source in Sector 9 of the storage ring. Seven sample magnets were irradiated to various absorbed doses, ranging from 30 Mrad to approximately $280 \mathrm{Mrad}$, during multiple trials.

The magnet irradiation configuration, placed inside the experimental hutch, consisted of a water-cooled magnet holder and a water-cooled aluminum spreader. The configuration was placed on a pedestal, which allowed for alignment of the sample magnet to the height of the beam window. Figure 5 provides a schematic diagram of the steel magnet holder with copper cooling tubes, and Figure 6 provides a schematic diagram of the aluminum spreader with copper cooling tubes. The aluminum spreader was placed directly after the beam window in the experimental hutch, between the window and the magnet holder. The purpose of the aluminum spreader was to diffuse the dose received by the sample magnet, allowing a more uniform irradiation of the magnet. A PHOTON [37] calculation showed that the 1-cm-thick spreader alleviated some of the heat load to the magnet by cutting the peak flux to the sample magnet from $10^{16}$ photons/second/keV to $10^{14}$ photons/second/keV. Figure 7 provides the graphical results of the PHOTON calculation. The magnet holder was placed directly after the aluminum spreader. A photograph of the irradiation configuration is shown in Figure 8. During irradiation the sample magnet was wrapped in cardboard and placed in the center opening of the magnet holder, as shown in the photograph.

The temperature during the irradiation had to be kept below $50^{\circ} \mathrm{C}$ due to the temperature constraint of the radiachromic films that were used for dosimetry purposes. The temperature also had to be controlled due to the temperature sensitivity of the sample magnets themselves, in terms of temperature-induced demagnetization. Chilled water was circulated through copper cooling tubes to control the temperature of the aluminum spreader as well as the magnet holder. As a result of the chilled magnet holder, the temperature of the sample magnet was maintained at $45^{\circ} \mathrm{C}$ during irradiation, well below the $50^{\circ} \mathrm{C}$ requirement. A temperature measurement system, comprised of a control program installed on a PC and thermocouples, was used to monitor temperatures. Thermocouples were placed on the top and bottom of the aluminum spreader, on both sides of the sample magnet, and on the top of the magnet holder. A sixth thermocouple was used to monitor the ambient air temperature inside the experimental hutch. Prior to irradiation of the sample magnets, the temperature of the chilled water had to be adjusted to a level that would keep the sample magnet temperature well below $50^{\circ} \mathrm{C}$ during irradiation. A series of "dummy" magnet irradiations was done for this purpose. Stainless steel "dummy" magnets were placed inside the magnet holder and irradiated while the temperatures were closely monitored. Numerous "dummy" irradiations were performed 
until the temperature of the water chiller was adjusted to a point that allowed for stabilized magnet temperatures below $50^{\circ} \mathrm{C}$ during irradiation. Figure 9 provides a sample of a temperature stabilization plot.

Along with temperature stabilization, a preliminary dose rate had to be determined prior to irradiation of the sample magnets. Radiachromic films were used to determine an approximate dose rate to the sample magnet, which was normalized, or based on the irradiation time and the beam current. Radiachromic films were placed on the top and the bottom of a sample permanent magnet that was then placed inside the magnet holder and irradiated for a specified period of time. The average normalized dose rate was determined to be approximately $0.15 \mathrm{Mrad} / \mathrm{hr} / \mathrm{mA}$. This dose rate was used to determine the total absorbed dose to the magnet for extended periods of irradiation.

A PHOTON [37] calculation was done to determine the bending magnet radiation spectrum that was used to irradiate the sample magnets at APS beamline $9 \mathrm{BM}$. The calculation also provided a calculated dose rate to the sample magnets that could be compared to the dose rate measured using the radiachromic films. The calculation was done for the specific parameters of APS beamline 9 BM, including the width, thickness, and composition of the windows that the beam passes through as it enters the experimental hutch. Figure 7 displays the calculated bending magnet irradiation spectrum for APS beamline $9 \mathrm{BM}$. The peak energy is approximately $40 \mathrm{keV}$ with the $1-\mathrm{cm}$ aluminum spreader in place. The calculated tissue dose to the magnets was determined to be approximately $36.5 \mathrm{Mrad} / \mathrm{hr}$. Because only $1 / 3$ of the beam is incident on the magnet, the tissue dose to the magnet is $1 / 3$ of $36.5 \mathrm{Mrad} / \mathrm{hr}$, or approximately $12 \mathrm{Mrad} / \mathrm{hr}$. This is consistent with the normalized absorbed dose measured using the radiachromic films for an average beam current of approximately $80 \mathrm{~mA}$.

Seven sample magnets were irradiated with x-rays at APS beamline 9 BM to various absorbed doses ranging from approximately $30 \mathrm{Mrad}$ to $280 \mathrm{Mrad}$. Two of the sample magnets were irradiated using a "stepwise" irradiation procedure of three, three-hour irradiations, resulting in a total irradiation time of nine hours. The other sample magnets were irradiated as one continuous irradiation. Table 3 provides a record of the irradiated sample magnets along with the associated absorbed doses. The absorbed doses to the sample magnets were determined using the $0.15-\mathrm{Mrad} / \mathrm{hr} / \mathrm{mA}$ normalized dose rate approximation, due to the response limit of radiachromic films at dose levels greater than $10 \mathrm{Mrad}$. The $0.15-\mathrm{Mrad} / \mathrm{hr} / \mathrm{mA}$ normalized dose rate approximation was determined by taking an average of normalized dose rates measured using radiachromic films.

Five measurements of the intrinsic remnant induction were taken for each sample magnet prior to irradiation. These measurements were also taken for the two control magnets. The average of these measurements served as initial readings to be compared to measurements taken after irradiation. Six radiachromic films were also prepared for the irradiation. These films provided an approximate absorbed dose to the magnet. Two of the films were placed on the top of the magnet and two were placed on the bottom of the magnet before the magnet was placed inside the holder. The other two radiachromic films served as controls. With the radiachromic films in place, a layer of cardboard was 
wrapped around the magnet, and the magnet was placed inside the holder. The water chiller was turned on inside the experimental hutch prior to irradiation to allow the temperatures of the holder, spreader, and magnet to come down to acceptable levels. Temperatures were monitored during the entire irradiation and maintained below $45^{\circ} \mathrm{C}$. A sample plot of the monitored temperatures is given in Figure 9.

Following irradiation for the specified period of time, the magnet was removed and allowed to cool to room temperature in the lab. The radiachromic films were removed and read to determine an approximate absorbed dose to the sample magnet. Intrinsic remnant induction measurements were then taken for the sample magnet and the control magnets. The average of these "final" readings was compared to the "initial" readings taken prior to irradiation, using the pooled t-test described previously, to determine if any measurable radiation-induced demagnetization had occurred. This process was then repeated for the next irradiation.

\section{Results and Analysis of X-ray Irradiation}

Intrinsic remnant induction measurements for each sample magnet prior to x-ray irradiation compared to measurements following irradiation revealed small, but not insignificant levels of variation. Table 3 shows the deterioration of the intrinsic remnant induction as a percent change for each x-ray irradiation as compared to the percent change observed in the unirradiated control magnets. The same results are displayed in a graphical form in Figure 10. This small, but not insignificant level of variation averaged around a $0.2 \%$ difference and was observed in approximately half of the $\mathrm{x}$-ray irradiations performed.

As stated previously, a $0.5 \%$ change in the magnetic field of insertion devices typically cannot be tolerated [5]. Therefore, a $0.2 \%$ change would not be considered insignificant. The fact that the $0.2 \%$ variation only occurred in the sample magnets and not the control magnets also indicates a significant level of variation. However, a $0.2 \%$ level of variation is at the edge of the precision capabilities of the measurement device, or fluxmeter, rendering the observed variations statistically insignificant. In other words, due to the precision level of the fluxmeter, the observed variations cannot be solely attributed to radiation-induced demagnetization and are determined statistically insignificant as a result.

The observed variations measured from the stepwise irradiations of Magnet 13A and Magnet 14A did not display a cumulative effect, suggesting that an annealing process was taking place between irradiations. However, continuous irradiation of the sample magnets did not reveal the existence of an annealing process. If an annealing process were responsible for the noncumulative effect observed during the stepwise irradiation procedure, we would expect to see larger changes in the intrinsic remnant induction of the sample magnets for longer continuous irradiations. The continuous irradiation of a sample magnet for twenty-four hours did not reveal any such changes in the intrinsic remnant induction, indicating that during x-ray irradiation an annealing process is not responsible for the observed variations in the intrinsic remnant induction measurements. 
The average $0.2 \%$ level of variation was observed during some of the stepwise irradiations, as well as during some of the continuous irradiations, over a range of irradiation times from six hours to seventeen hours. The noncumulative effect observed during the stepwise irradiation may be due to the precision capabilities of the instrument.

Statistical inference and the pooled $t$-test were used to compare the preirradiation means of the intrinsic remnant induction measurements to the means found after x-ray irradiation of the sample magnets. Many of the comparisons done using the test revealed evidence of differences between the means. However, the average $0.2 \%$ level of variation, or difference between the means, is at the edge of the precision capabilities of the fluxmeter. Therefore, although differences between the means may exist, they are probably attributable to the precision level of the instrument rather than radiation-induced demagnetization.

Previous to this study a pure $\mathrm{x}$-ray irradiation of $\mathrm{Nd}-\mathrm{Fe}-\mathrm{B}$ sample magnets had never been done. Numerous studies involving the irradiation effects of direct electron beams on $\mathrm{Nd}$ Fe-B permanent magnet samples have been conducted, but direct electron beam irradiation yields results for situations when the particle beam is lost directly on the magnet. This, as mentioned earlier, is unrealistic at today's synchrotron radiation source facilities.

Radiation dose measurements of the insertion devices at the APS indicate the largest component of the absorbed dose to the devices is directed toward the downstream end of the device, likely the result of the greater amount of synchrotron radiation present at the downstream end [15]. With x-rays likely to be the largest absorbed dose component to the permanent magnets used in the insertion devices, pure $x$-ray irradiation, rather than direct electron beam irradiation, is a more realistic approach to simulate the irradiation of the permanent magnets under routine storage ring conditions.

\section{Neutron Irradiation}

Neutron irradiation of the Nd-Fe-B permanent magnets was done in collaboration with Oak Ridge National Laboratory's (ORNL) Californium User Facility for Neutron Science. Sample permanent magnets were systematically irradiated with ${ }^{252} \mathrm{Cf}$ sources to incremental fluence levels in a fast-neutron spectrum, as well as a thermal-neutron spectrum. ORNL's Californium User Facility for Neutron Science provided a userfriendly neutron irradiation facility allowing for ideal irradiation configurations and experimental conditions. With a neutron emission rate of $2.31 \times 10^{6}$ neutrons $/ \mathrm{s} / \mu \mathrm{g}$ and a peak energy of approximately $1-2 \mathrm{MeV},{ }^{252} \mathrm{Cf}$ proved to be an ideal source for both the fast-neutron and the thermal-neutron irradiation of the sample magnets. Irradiations were performed inside a hot cell. The particular hot cell used for the sample magnet irradiations was Cell $\mathrm{C}$ with interior dimensions of 20 feet wide, 33 feet long, and 24 feet high. Five feet of high-density concrete served as the cell's outer shielding, while a fivefoot-thick window of lead glass and water allowed for visual inspection of the irradiation configuration from outside the hot cell. The temperature during the irradiation was held constant within the hot cell due to the air conditioned building and the large amount of 
thermal inertia within the cell. All temperature measurements within the cell were on the order of $25^{\circ} \mathrm{C}$. This allowed for the control of any temperature-induced demagnetization of the sample magnets. An area was set up just outside of Cell C's viewing window to check for activation of the sample magnets as they were removed from the cell. Another area was set up outside of the entrance to Cell $\mathrm{C}$ for the magnetic measurements of the sample and control magnets.

For the very short irradiations, when sources with small ${ }^{252} \mathrm{Cf}$ content were used, activation within the hot cell was not an issue for personnel access. Therefore the cell could be opened and the magnets could be placed inside. For the fast-neutron irradiation sample magnets were placed on ring stands inside the hot cell. Two rings stands were placed side-by-side while another set of ring stands, in the same configuration, were placed at a distance of approximately $60 \mathrm{~cm}$ away from the first set. This allowed for the ${ }^{252} \mathrm{Cf}$ source to be placed in the middle of the ring-stand configuration so that the sourceto-sample distance was $29.5 \mathrm{~cm}$, simulating a point-source configuration. A schematic diagram of the fast-neutron irradiation configuration is shown in Figure 11. A photograph of the fast-neutron irradiation configuration is given in Figure 12.

For longer irradiations using sources with high ${ }^{252} \mathrm{Cf}$ content, placement and removal of the sample magnets in the hot cell had to be done remotely due to the activation within the cell that prohibited personnel access. The magnets were moved in and out of the hot cell through a transport chute. Remote manipulators were then used to position the sample magnets and the sources. Figure 13 provides a photograph of the transport chute and the remote manipulators.

Fluence estimates were calculated prior to irradiation using MCNP Version 4B and were based on the source configuration, ${ }^{252} \mathrm{Cf}$ content, and the total irradiation time. Tables 4 and 5 give the ${ }^{252} \mathrm{Cf}$ content and time parameters that were used in the MCNP incremental fluence calculations for the fast- and thermal-neutron irradiations, respectively, along with the resulting fluences for each irradiation step. The last column in each table represents the total fluence to which the magnets were subjected throughout the stepwise irradiation process. The last two rows of each table indicate data for the second set of magnets that were irradiated.

Calculated MCNP fluxes were compared to actual flux measurements that were done using wire irradiation, in order to calibrate the MCNP simulations. Indium wires were irradiated in a fast-neutron spectrum, a thermal-neutron spectrum, and an intermediateneutron spectrum. Wires were irradiated in the fast-neutron spectrum for approximately 24 hours using approximately $46 \mathrm{mg}$ of ${ }^{252} \mathrm{Cf}$. In the thermal neutron spectrum Indium wires were irradiated for approximately six days using approximately $49 \mathrm{mg}$ of ${ }^{252} \mathrm{Cf}$, while in the intermediate spectrum wires were irradiated for approximately 22 hours using approximately $49 \mathrm{mg}$ of ${ }^{252} \mathrm{Cf}$. Following each irradiation, the wires were analyzed to determine the measured fast-neutron as well as the thermal-neutron flux component of the spectrum by analyzing ${ }^{115} \mathrm{In}$ and ${ }^{116}$ In activities. The measured fluxes were then compared to the fluxes that were calculated using MCNP. Table 6 provides the 
comparison between the calculated fluxes using MCNP and the flux measurements done using wire irradiation.

Prior to irradiation, intrinsic remnant induction readings were taken for each of the sample magnets along with the control magnets. Ten readings were taken for each magnet. The average of these readings served as the initial readings to be compared to the readings taken following the irradiation. The sample magnets were wrapped in 3-mmthick cardboard to ensure safe handling and allow for easier manipulation within the hot cell. The control magnets were set aside, away from any potential irradiation sources, while the sample magnets to be irradiated were placed inside the hot cell for irradiation.

Following an irradiation, the sample magnets were removed from the hot cell via the transport chute, and checked for activation. Intrinsic remnant induction readings were taken for each of the sample magnets along with the control magnets. Ten readings were taken for each magnet. The average of these readings served as the final readings that were compared to the "initial" readings taken prior to irradiation. The comparisons were used to determine if the neutron irradiation had resulted in radiation-induced demagnetization of the sample magnets. Once all of the final readings were taken, the magnets were placed back inside the hot cell for the next irradiation in the cycle at a higher fluence level. The sample magnets were flipped over for every irradiation so that each face of the magnets faced the ${ }^{252} \mathrm{Cf}$ sources during every other irradiation. This allowed for a more uniform irradiation of the magnets.

Four sample magnets along with two control magnets were used for the fast-neutron irradiation. Only two sample magnets and one control magnet were used in the subsequent thermal-neutron irradiation. The experimental procedure for the thermal neutron irradiation was identical to the fast-neutron irradiation procedure. Approximately twenty-two centimeters of polyethylene moderation was placed between the ${ }^{252} \mathrm{Cf}$ source and the sample magnets for the thermal-neutron irradiation in order to thermalize the neutron spectrum. Polyethylene blocks were also placed around the entire irradiation configuration to maximize the neutron flux. A schematic diagram of the thermal neutron irradiation configuration is given in Figure 14. A photograph of the thermal-neutron irradiation configuration with the added polyethylene is given in Figure 15.

The fast-neutron irradiation consisted of a total of eight irradiations. For each of the first six irradiations, four sample magnets were irradiated in two-decade total fluence increments ranging from approximately $10^{6} \mathrm{n} / \mathrm{cm}^{2}$ to $10^{14} \mathrm{n} / \mathrm{cm}^{2}$. The final two irradiations were done using a second set of four sample magnets. This second set of magnets was irradiated to total fluences of approximately $2 \times 10^{13} \mathrm{n} / \mathrm{cm}^{2}$ and $4 \times 10^{13} \mathrm{n} / \mathrm{cm}^{2}$. The thermal-neutron irradiation consisted of a total of thirteen irradiations. The sample permanent magnets were irradiated in total fluence increments ranging from approximately $10^{6} \mathrm{n} / \mathrm{cm}^{2}$ to $10^{12} \mathrm{n} / \mathrm{cm}^{2}$. 


\section{Results and Analysis of Neutron Irradiation}

Intrinsic remnant induction measurements for each magnet prior to fast-neutron irradiation compared to measurements following irradiation revealed significant changes for fluence levels greater than $2 \times 10^{13} \mathrm{n} / \mathrm{cm}^{2}$. Table 7 provides the deterioration of intrinsic remnant induction as a percent change for each irradiation step as compared to the percent change observed in the unirradiated control magnets. Figure 16 shows the same results in a graphical format.

As stated previously, changes greater than $0.2 \%-0.3 \%$ would be considered statistically significant due to the precision capabilities of our magnetic measuring device, the fluxmeter. The statistical error associated with each data point due to the precision capabilities of the fluxmeter is approximately $0.25 \%$. This is based on the $99 \%$ confidence interval and the average standard deviation $(\sigma)$ of the fluxmeter. As stated previously, measured changes in the intrinsic remnant induction greater than 0.006 will be detected by the fluxmeter and considered statistically significant. Therefore, for changes greater than $0.2 \%-0.3 \%$ the observed decrease in the intrinsic remnant induction of the sample magnets, measured using the fluxmeter, could be attributed to the irradiation effects, rather than to statistical fluctuations within the instrument. An error value of $0.25 \%$ is fairly significant in relation to the initial data points, representing the first few fast-neutron irradiations at the lower fluences, where the percent changes between the initial and final intrinsic remnant induction measurements are considerably small. In other words, for the irradiations below $1 \times 10^{12} \mathrm{n} / \mathrm{cm}^{2}$, the statistical error plays a large role in the percent changes between the initial and final intrinsic remnant induction readings. However, for the fast-neutron irradiations at fluences above $1 \times 10^{12} \mathrm{n} / \mathrm{cm}^{2}$, the statistical errors are relatively small compared to the percent changes between the initial and final intrinsic remnant induction readings. For these larger fluences the observed percent changes can be attributed to the radiation damage rather than to statistical variations, indicating that the fast-neutron irradiation resulted in radiation-induced demagnetization of the sample magnets.

During irradiation of the first set of sample permanent magnets in the fast-neutron spectrum, significant changes were not evident until a fluence level of approximately $1.61 \times 10^{14} \mathrm{n} / \mathrm{cm}^{2}$. At this point, the differences between the initial intrinsic remnant induction measurements and the final measurements were well over $10 \%$, while the control magnets showed no signs of change. Due to the very large gap between the $1.61 \times 10^{14} \mathrm{n} / \mathrm{cm}^{2}$ point and the previous data point at $1.83 \times 10^{12} \mathrm{n} / \mathrm{cm}^{2}$ where statistically insignificant changes were indicated, it was determined that more points were needed. Because this particular set of magnets was already damaged at the $10^{14}$ fluence level, another set of magnets was irradiated twice, which resulted in data points at approximately $2.33 \times 10^{13} \mathrm{n} / \mathrm{cm}^{2}$ and $4.07 \times 10^{13} \mathrm{n} / \mathrm{cm}^{2}$. Both of these points indicated significant changes in the intrinsic remnant induction of the sample magnets. An average percent difference of $0.6 \%$ between the initial and final intrinsic remnant induction measurements was found at the $2.33 \times 10^{13} \mathrm{n} / \mathrm{cm}^{2}$ fluence level, and an average percent difference of $0.8 \%$ was found at the $4.07 \times 10^{13} \mathrm{n} / \mathrm{cm}^{2}$ fluence level. 
According to Okuda et al. [5], a $0.5 \%$ change in the magnetic field of the insertion devices typically cannot be tolerated. The results of this study indicate that for fastneutron fluences of $2.33 \times 10^{13} \mathrm{n} / \mathrm{cm}^{2}$, the $0.5 \%$ level of change is reached, and the percent change increases with rising fluence. These results are similar to results obtained by Cost et al. [10]. From the present investigation we also know that annealing does not occur, as the damage does not cure itself over time. Intrinsic remnant induction measurements of the damaged magnets were taken two days after the damage occurred and again two and a half weeks after the damage occurred. The results of the these measurements are given in Figure 17, which shows the relative change between the intrinsic remnant induction measurements immediately following damage and the measurements taken two days and two and a half weeks later.

The fact that annealing effects do not exist indicates that the damage is permanent and most likely related to either transmutation or permanent dislocation. This point is further supported by the results indicated by the thermal-neutron irradiation. Intrinsic remnant induction measurements for each magnet prior to thermal-neutron irradiation compared to measurements following irradiation revealed small, insignificant levels of variation. Table 8 provides the deterioration of intrinsic remnant induction as a percent change for each thermal-neutron irradiation step as compared to the percent change observed in the unirradiated control magnets. Figure 18 shows the same results in a graphical format.

Table 8 shows an average percent difference in the irradiated sample magnets of $0.03 \%$. A $0.03 \%$ level of variation is below the precision capabilities of the fluxmeter. As stated previously, the statistical error associated with each measurement due to the precision capabilities of the fluxmeter is approximately $0.25 \%$, based on the $99 \%$ confidence interval and the average standard deviation $(\sigma)$ of the fluxmeter. Therefore, an observed decrease in the intrinsic remnant induction of the sample magnets, measured using the fluxmeter, could be attributed to the irradiation of the magnets, rather than to statistical fluctuations within the instrument, for changes greater than $0.25 \%$. In this case $0.03 \%$ is well below $0.25 \%$. As a result, the measured changes in the intrinsic remnant induction following thermal-neutron irradiation are not statistically significant and are most likely attributable to the precision of the fluxmeter rather than radiation-induced demagnetization.

The sample permanent magnets were irradiated to a total thermal-neutron fluence of $3.34 \times 10^{12} \mathrm{n} / \mathrm{cm}^{2}$, and no radiation-induced demagnetization was observed, while radiation-induced demagnetization was observed at a fast-neutron fluence of $2.33 \times 10^{13}$ $\mathrm{n} / \mathrm{cm}^{2}$. The damage mechanisms that cause the demagnetization of the sample magnets are transmutation and dislocation of atoms. When an incoming neutron "dislocates" an atom in the lattice and disturbs the magnetic domain, dislocation is said to occur. Transmutation results when an incoming neutron is absorbed into the nucleus of the atom and a new element is produced. As a result of new element production, transmutation effects are considered irreversible, while the effects of dislocation are to some extent reversible. In this particular case, nonexistent annealing effects would indicate that the damage is irreversible, thereby suggesting transmutation as the possible mechanism of 
damage. However, a permanent dislocation would also explain the nonexistent annealing effects.

Detailed analysis of absorption cross-sections and elastic scattering cross-sections reveals more insight into the mechanism of damage. Thermal neutrons have large neutron absorption cross sections that are two orders of magnitude higher than fast-neutron absorption cross sections for most elements. These large neutron absorption cross sections increase the likelihood of transmutation. As a result, the transmutation mechanism of damage related to neutron absorption cross sections is usually associated with thermal-neutron irradiation. The elastic scattering cross section is almost a constant as a function of incoming neutron energy for most elements. Therefore, the probability that a neutron will be scattered from an atom is constant regardless of whether it is a fast or a thermal neutron. However, during elastic scattering, a fast neutron transfers more energy into an atom than a thermal neutron does, resulting in broken bonds within the lattice. The probability of elastic scattering resulting in broken bonds within the lattice causing dislocation is greater for fast neutrons than thermal neutrons. In this particular investigation, radiation-induced demagnetization was observed as a result of fast-neutron irradiation. If the primary mechanism of damage were transmutation, the deterioration would occur at a much lower thermal-neutron flux level due to the higher absorption cross section of thermal neutrons. As a result we conclude that the magnetic deterioration is primarily a phenomena due to a permanent dislocation of the atoms caused by the elastic scattering of fast neutrons that disturbed the magnetic domains.

\section{Summary and Conclusions}

The high remanence, or residual magnetic induction, and the intrinsic coercivity of $\mathrm{Nd}$ Fe-B permanent magnets makes them desirable for use in insertion devices, but the high radiation environment within high-energy storage rings makes determination of the degree of radiation sensitivity, as well as the mechanisms responsible for radiationinduced demagnetization, essential. For this study, sample Nd-Fe-B permanent magnets were irradiated up to an absorbed dose of $700 \mathrm{Mrad}$ using ${ }^{60} \mathrm{Co} \gamma$-rays and up to an absorbed dose of approximately $280 \mathrm{Mrad}$ using the APS bending magnet x-rays. Sample magnets were also irradiated with fast neutrons up to a total fast fluence of $1.61 \times 10^{14}$ $\mathrm{n} / \mathrm{cm}^{2}$, and with thermal neutrons up to a total thermal fluence of $2.94 \times 10^{12} \mathrm{n} / \mathrm{cm}^{2}$. For the $x$-ray and the $\gamma$-ray irradiations, a variation of less than $0.2 \%$ was found to exist, indicating that radiation-induced demagnetization had occurred. However, the level of variation was at the edge of the precision capabilities of the measuring instrument so it could not be solely attributed to the radiation damage and was more likely explained by the precision capabilities of the instrument. For the fast-neutron irradiation intrinsic remnant induction measurements for each magnet prior to fast-neutron irradiation compared to measurements following irradiation revealed significant changes for fluence levels greater than $2 \times 10^{13} \mathrm{n} / \mathrm{cm}^{2}$. Intrinsic remnant induction measurements for each magnet prior to thermal-neutron irradiation compared to measurements following irradiation for fluence levels up to $3 \times 10^{12} \mathrm{n} / \mathrm{cm}^{2}$ revealed small, insignificant levels of variation that were most likely attributable to the precision capabilities of the measuring instrument. 
The results of this study, along with previous investigations, indicate varying degrees of degradation in the intensity of magnetization of Nd-Fe-B permanent magnets based on the irradiation source, the total absorbed dose to the magnets, and the precision capabilities of the measuring device, to name a few of the variants. Results from previous investigations displayed a wide variation in the sensitivity to radiation, dependent on the manufacturing process or magnet vendor. Among the different Nd-Fe-B compounds, it was also found in previous studies that those with higher remanence and lower coercivity were more susceptible to demagnetization from an electron beam.

This study, along with previous studies, attempted to quantify the radiation-induced demagnetization of $\mathrm{Nd}-\mathrm{Fe}-\mathrm{B}$ permanent magnets from $\gamma$-rays, $\mathrm{x}$-rays, and neutrons. Due to the many factors involved in the determination of radiation-induced demagnetization of $\mathrm{Nd}-\mathrm{Fe}-\mathrm{B}$ permanent magnets, along with great number of variations within each experimental procedure, it is difficult to make comparisons between investigations. The important point for each study is that a $0.5 \%$ change in the magnetic field of the insertion devices used in many synchrotron light sources typically cannot be tolerated. Therefore, even small variations of $0.1 \%-0.2 \%$ are important as long as they can be determined statistically significant. For this study, the average $0.1 \%-0.2 \%$ percent change in the intrinsic remnant induction measurements found in the $\mathrm{x}$-ray and $\gamma$-ray irradiations was at the edge of the precision capabilities of the instrument and therefore could not be solely attributed to the radiation-induced demagnetization of the sample magnet. As a result the changes were determined statistically insignificant. For fast-neutron irradiation fluence levels of $2 \times 10^{13} \mathrm{n} / \mathrm{cm}^{2}$ and greater, the percent changes found in the intrinsic remnant induction measurements were found to be over $0.5 \%$ and were determined statistically significant. Thermal-neutron irradiation up to a total thermal-neutron fluence of $2.94 \times 10^{12} \mathrm{n} / \mathrm{cm}^{2}$ revealed an average percent difference in the irradiated sample magnets of $0.03 \%$, which is below the precision capabilities of the measuring instrument. Therefore, the measured changes in the intrinsic remnant induction following thermalneutron irradiation were determined statistically insignificant. The statistically significant radiation-induced demagnetization observed as a result of fast-neutron irradiation was concluded to primarily be the result of a phenomena caused by the permanent dislocation of the atoms in the lattice that disturbed the magnetic domains.

While only the fast-neutron irradiation results in this investigation could be determined statistically significant, this study extends beyond the scope of previous investigations and provides useful results. This investigation provided the first complete study of the radiation-induced demagnetization of $\mathrm{Nd}-\mathrm{Fe}-\mathrm{B}(\mathrm{N} 38 \mathrm{H})$ sample magnets from all types of radiation that the magnets are subjected to under normal operating conditions within synchrotron radiation sources. This study also differentiated between the effects of fastneutron and thermal-neutron irradiation. In the present investigation ${ }^{60} \mathrm{Co}$ irradiation went as far as $700 \mathrm{Mrad}$. The first investigation of the radiation-induced demagnetization of $\mathrm{Nd}-\mathrm{Fe}-\mathrm{B}$ sample magnets using a pure $\mathrm{x}$-ray source rather than direct electron beam irradiation was conducted. Specific fast-neutron irradiation as well as thermal-neutron irradiation was also conducted. This work also considered temperature control during neutron irradiation as an important factor. The neutron irradiations were nonreactor-based 
irradiations, allowing for pure and controlled conditions similar to the conditions that the sample magnets are subjected to in synchrotron radiation sources.

\section{Acknowledgements}

The authors would like to express our deepest thanks to members of the Complex Material Consortium Collaborative Access Team at APS beamline 9 BM for allowing us to use their beamline for the x-ray irradiation portion of the study. We would like to thank Jeff Collins of the APS Experimental Facilities Division for his help with the programming and set-up of the temperature measurement system used during the x-ray irradiation. We would also like to thank Rod Salazar for his help with the experimental set-up for the $\mathrm{x}$-ray irradiation.

This work was supported by the U.S. Department of Energy, Office of Basic Energy Sciences, under Contract W-31-109-ENG-38. 


\section{References}

[1] The Advanced Photon Source - A National Synchrotron Radiation Research Facility at Argonne National Laboratory, ANL/APS/TB-25-Rev., Argonne National Laboratory, 1997.

[2] B. Lai, A. Khounsary, R. Savoy, L. Moog, and E. Gluskin, Undulator A Characteristics and Specifications, ANL/APS/TB-3, Argonne National Laboratory, 1993.

[3] R.D. Brown, and J.R. Cost, Radiation-Induced Changes in Magnetic Properties of Nd-Fe-B Permanent Magnets, IEEE Trans. Magn. 25 (1989) 3117.

[4] P. Colomp, T. Oddolaye, and P. Ellaeume, Demagnetization of Permanent Magnets to $180 \mathrm{MeV}$ Electron Beam, ESRF/MACH/93-09 (1993).

[5] S. Okuda, K. Ohashi, and N. Kobayashi, Effects of electron-beam and $\gamma$-ray irradiation on the magnetic flux of $\mathrm{Nd}-\mathrm{Fe}-\mathrm{B}$ and $\mathrm{Sm}-\mathrm{Co}$ permanent magnets, Nucl. Instr. and Meth. B 94 (1994) 227.

[6] J. Chavanne, P. Elleaume, and P. Van Vaerenbergh, Partial Demagnetization of ID6 and Dose Measurements on Certain IDs, ESRF Machine Technical Note 11996/ID (1996).

[7] H.B. Luna, X.K. Maruyama, N.J. Colella, J.S. Hobbs, R.S. Hornady, B. Kulke, and J.V. Palomar, Bremsstrahlung Radiation Effects in Rare Earth Permanent Magnets, Nucl. Instr. and Meth. A 285 (1989) 349-354.

[8] J. Pfluger, G. Heintze, and I. Vasserman, Search for possible radiation damage on a $\mathrm{NdFeB}$ permanent magnet structure after two years of operation, Rev. Sci, Instrum. 66 (1995) 1946.

[9] K. Boockman, M. Liehr, W. Rodewald, E. Salzborn, M. Schlapp, and B. Wall, Effect of $\gamma$-radiation on Sm-Co and Nd-Dy-Fe-B magnets, Journal of Magnetism and Magnetic Materials 101 (1991) 345-346.

[10] J.R. Cost, R.D. Brown, A.L. Giorgi, and J.T. Stanley, Effects of Neutron Irradiation on Nd-Fe-B Magnetic Properties, IEEE Trans. Magn. 24 (1988) 2016.

[11] R.D. Brown, J.R. Cost, G.P. Meisner, and E.G. Brewer, Neutron irradiation study of Nd-Fe-B permanent magnets made from melt-spun ribbons, J. Appl. Phys. 64 (1988) 5305.

[12] E.R. Moog, P.K. Den Hartog, E.J. Semones, and P.K. Job, Radiation Doses to Insertion Devices at the Advanced Photon Source, Proc. of Tenth National Conf. on Synch. Radiat. Inst. (1997) 219. 
[13] M. Cornacchia et al., Performance and Design Concepts of a Free Electron Laser Operating in the x-ray Region, Presented at LASE97, San Jose, CA (1997).

[14] A. Fasso, S. Rokni, and V. Vylet, Radiation Studies for a High Energy Free Electron Laser, Proc. of SARE3, Tsukuba, Japan (1997) 233.

[15] J. Alderman, E. Semones, and P.K. Job, Radiation Dose Measurements of the Insertion Devices, ANL/APS/LS-283, Argonne National Laboratory, 2000.

[16] J. Ranft and W.R. Nelson, Hadron Cascades Induced by Electron and Photon Beams in the GeV Energy Range, Nucl. Instr. and Meth. A 257 (1987) 177.

[17] H. Winick, Synchrotron Radiation Sources - A Primer, World Scientific, Singapore (1994) 13.

[18] M. Pisharody, P.K. Job, S. Magill, J. Proudfoot, and R. Stanek, Measurements of gas bremsstrahlung from electron storage rings, Nucl. Instr. and Meth. A $\mathbf{4 0 1}$ (1997) 442-462.

[19] M. Pisharody, E. Semones, and P.K. Job, Dose measurements of bremsstrahlungproduced neutrons from thick targets, Nucl. Instr. and Meth. A 430 (1999) 542558.

[20] S. Takeda, K. Tsumori, N. Kimura, T. Yamamoto, T. Hori, T. Sawai, J. Ohkuma, S. Takamuku, T. Okada, K. Hayashi, and M. Kawanishi, IEEE Trans. Nucl. Sci. NS-32 (1985) 3219.

[21] J.M.D. Coey, Rare-Earth Iron Permanent Magnets, Oxford Science Publications, New York (1996).

[22] K.C. Humpherys, and A.D. Kantz, Radiachromic: A Radiation Monitoring System, Radiat. Phys. Chem. 9 (1977) 737-747.

[23] K.C. Humpherys, J.D. Rickey, and R.L. Wilcox, Humidity Effects on the Dose Response of Radiachromic Nylon Film Dosimeters, Radiat. Phys. Chem. 35 (1990) 713-715.

[24] J.H. O'Donnell, Chemistry of Radiation Degradation of Polymers, Proc. of ACS Symposium Series 475 (1990) 402.

[25] W.L. McLaughlin, J.C. Humphreys, D. Hocken, and W.J. Chappas, Radiochromic Dosimetry for Validation and Commissioning of Industrial Radiation Processes, Radiat. Phys. Chem. 31 (1988) 505-514. 
[26] W.L. McLaughlin, A. Miller, F. Abdel-Rahim, and T. Preisinger, Plastic Film Materials for Dosimetry of Very Large Absorbed Doses, Radiat. Phys. Chem. 25 (1985) 729-748.

[27] W.L. McLaughlin, National Institute of Standards and Technology, Gaithersburg, MD, private communication (1997).

[28] W.L. McLaughlin, A. Miller, R.M. Uribe, S. Kronenberg, and C.R. Siebentritt, Energy Dependence of Radiochromic Dosimeter Response to X- and $\gamma$-Rays, Proc. of an International Symposium on High-Dose Dosimetry, Vienna (1985) 397.

[29] W.L. McLaughlin, J.C. Humphreys, B.B. Radak, A. Miller, and T.A. Olejnik, The Response of Plastic Dosimeters to Gamma Rays and Electrons at High Absorbed Dose Rates, Radiat. Phys. Chem. 14 (1979) 535-550.

[30] Chen Wenxiu, Jia Haishen, and W.L. McLaughlin, Response of Radiochromic Film Dosimeters to Electron Beams in Different Atmospheres, Proc. of an International Symposium on High-Dose Dosimetry, Vienna (1985) 345.

[31] Instruction Manual Model 2130 Fluxmeter, Revision 0 Starting with Serial Number 31309, Magnetic Instrumentation Inc., Indianapolis, IN (1998).

[32] D.W. Carnegie and J. Timpf, Characterizing Permanent Magnet Blocks with Helmholtz Coils, Nucl. Instr. and Meth. A 319 (1992) 97-99.

[33] M. Talvite, O.P. Kähkönen, S. Mäkinen, H. Rajainmäki, M. Manninen, and V. Lindroos, Magnetic Flux Loss in Nd-Fe-B Magnets Irradiated with $20 \mathrm{MeV}$ Protons, Journal of Magnetism and Magnetic Materials 102 (1991) 323-330.

[34] A. Hütten, Processing, Structure, and Property Relationships in Nd-Fe-B Magnets, JOM (March 1992) 11-15.

[35] D. Montgomery and G. Runger, Applied Statistics and Probability for Engineers, Second Edition, John Wiley \& Sons Inc., New York (1999) 390.

[36] J. Puhl, National Institute of Standards and Technology, Gaithersburg, MD, private communication (1999).

[37] D. Chapman, N. Gmür, N. Lazarz, and W. Thomlinson, PHOTON Code, Nucl. Instr. and Meth. A 266 (1988) 191. 
Table 1: Magnet and Coil Parameters

Magnet Parameters:

Average Dimensions:

\begin{tabular}{|llc|}
\hline & Length & $5.01 \mathrm{~cm}$ \\
\hline & Width & $4.75 \mathrm{~cm}$ \\
\hline & Thickness & $0.675 \mathrm{~cm}$ \\
\hline & & \\
\hline & Length $\mathrm{x}$ Width $\mathrm{x}$ Thickness & $16.06 \mathrm{~cm}^{3}$ \\
\hline \hline Coil Parameters: & \\
\hline Coil Resistance & $4.90 \mathrm{Ohms}$ \\
\hline Helmholtz Constant & 0.161 \\
\hline Diameter & $20.3 \mathrm{~cm}$ \\
\hline
\end{tabular}


Table 2: Gamma Irradiation - Change in Intrinsic Remnant Induction

\begin{tabular}{|c|c|c|}
\hline $\begin{array}{c}\text { Total Absorbed Dose } \\
\text { (Mrad) }\end{array}$ & \multicolumn{2}{|c|}{ Change in Intrinsic Remnant Induction } \\
\cline { 2 - 3 } & Irradiated Sample Magnets & Control Magnets \\
\hline \hline 100 & $0.039 \%$ & $0.020 \%$ \\
200 & $0.187 \%$ & $0.177 \%$ \\
300 & $0.118 \%$ & $0.098 \%$ \\
400 & $0.206 \%$ & $0.196 \%$ \\
500 & $0.196 \%$ & $0.118 \%$ \\
700 & $0.108 \%$ & $0.098 \%$ \\
\hline
\end{tabular}


Table 3: X-ray Irradiation - Change in Intrinsic Remnant Induction

\begin{tabular}{|c|c|c|c|}
\hline Magnet & Total Absorbed Dose & \multicolumn{2}{|c|}{ Change in Intrinsic Remnant Induction } \\
\cline { 3 - 4 } & $($ Mrad) & Irradiated Sample Magnets & Control Magnets \\
\hline \hline $13 \mathrm{~A}$ & 35 & $0.039 \%$ & $0.039 \%$ \\
& 68 & $0.275 \%$ & $0.020 \%$ \\
& 109 & $0.157 \%$ & $0.039 \%$ \\
\hline $14 \mathrm{~A}$ & 33 & $0.236 \%$ & $0.020 \%$ \\
& 75 & $0.118 \%$ & $0.059 \%$ \\
& 113 & $0.039 \%$ & $0.059 \%$ \\
\hline $15 \mathrm{~A}$ & 117 & $0.039 \%$ & $0.039 \%$ \\
\hline $16 \mathrm{~A}$ & 117 & $0.274 \%$ & $0.039 \%$ \\
\hline $19 \mathrm{~A}$ & 197 & $0.118 \%$ & $0.059 \%$ \\
\hline $20 \mathrm{~A}$ & 198 & $0.039 \%$ & $0.059 \%$ \\
\hline $21 \mathrm{~A}$ & 280 & $0.000 \%$ & $0.020 \%$ \\
\hline
\end{tabular}


Table 4: Fluence Results for Fast-Neutron Irradiation (MCNP Simulation)

\begin{tabular}{|c|c|c|c|}
\hline $\begin{array}{c}{ }^{252} \text { Cf Mass } \\
\text { (micrograms) }\end{array}$ & $\begin{array}{c}\text { Irradiation Time } \\
\text { (seconds) }\end{array}$ & $\begin{array}{c}\text { Incremental Fluence } \\
\left(\mathrm{n} / \mathrm{cm}^{2}\right)\end{array}$ & $\begin{array}{c}\text { Total Fluence } \\
\left(\mathrm{n} / \mathrm{cm}^{2}\right)\end{array}$ \\
\hline \hline 41.2 & $9.90 \mathrm{E}+01$ & $9.86 \mathrm{E}+05$ & $9.86 \mathrm{E}+05$ \\
467 & $8.67 \mathrm{E}+02$ & $9.78 \mathrm{E}+07$ & $9.88 \mathrm{E}+07$ \\
508.2 & $8.06 \mathrm{E}+04$ & $9.90 \mathrm{E}+09$ & $9.99 \mathrm{E}+09$ \\
29013.49 & $1.54 \mathrm{E}+05$ & $1.08 \mathrm{E}+12$ & $1.09 \mathrm{E}+12$ \\
28982.38 & $2.61 \mathrm{E}+05$ & $1.82 \mathrm{E}+12$ & $1.83 \mathrm{E}+12$ \\
47896.57 & $5.84 \mathrm{E}+05$ & $1.59 \mathrm{E}+14$ & $1.61 \mathrm{E}+14$ \\
\hline 47689.54 & $8.56 \mathrm{E}+04$ & $2.33 \mathrm{E}+13$ & $2.33 \mathrm{E}+13$ \\
47655.76 & $6.40 \mathrm{E}+04$ & $1.74 \mathrm{E}+13$ & $4.07 \mathrm{E}+13$ \\
\hline
\end{tabular}


Table 5: Fluence Results for Thermal-Neutron Irradiation (MCNP Simulation)

\begin{tabular}{|c|c|c|c|}
\hline $\begin{array}{c}{ }^{252} \text { Cf Mass } \\
\text { (micrograms) }\end{array}$ & $\begin{array}{c}\text { Irradiation Time } \\
\text { (seconds) }\end{array}$ & $\begin{array}{c}\text { Incremental Fluence } \\
\left(\mathrm{n} / \mathrm{cm}^{2}\right)\end{array}$ & $\begin{array}{c}\text { Total Fluence } \\
\left(\mathrm{n} / \mathrm{cm}^{2}\right)\end{array}$ \\
\hline \hline 3657.00 & $1.00 \mathrm{E}+01$ & $1.10 \mathrm{E}+06$ & $1.10 \mathrm{E}+06$ \\
3657.00 & $3.10 \mathrm{E}+02$ & $3.42 \mathrm{E}+07$ & $3.53 \mathrm{E}+07$ \\
3657.00 & $5.24 \mathrm{E}+03$ & $5.79 \mathrm{E}+08$ & $6.14 \mathrm{E}+08$ \\
3657.00 & $8.04 \mathrm{E}+03$ & $8.88 \mathrm{E}+08$ & $1.50 \mathrm{E}+09$ \\
3657.00 & $6.26 \mathrm{E}+04$ & $6.91 \mathrm{E}+09$ & $8.41 \mathrm{E}+09$ \\
30972.68 & $1.81 \mathrm{E}+04$ & $1.84 \mathrm{E}+10$ & $2.68 \mathrm{E}+10$ \\
30961.53 & $6.33 \mathrm{E}+04$ & $6.43 \mathrm{E}+10$ & $9.12 \mathrm{E}+10$ \\
48959.89 & $1.13 \mathrm{E}+04$ & $1.71 \mathrm{E}+10$ & $1.08 \mathrm{E}+11$ \\
48906.93 & $2.50 \mathrm{E}+05$ & $3.80 \mathrm{E}+11$ & $4.88 \mathrm{E}+11$ \\
48679.44 & $3.38 \mathrm{E}+05$ & $5.11 \mathrm{E}+11$ & $9.99 \mathrm{E}+11$ \\
48539.80 & $3.47 \mathrm{E}+05$ & $5.23 \mathrm{E}+11$ & $1.52 \mathrm{E}+12$ \\
48279.25 & $9.47 \mathrm{E}+05$ & $1.42 \mathrm{E}+12$ & $2.94 \mathrm{E}+12$ \\
48039.94 & $2.70 \mathrm{E}+05$ & $4.02 \mathrm{E}+11$ & $3.34 \mathrm{E}+12$ \\
\hline
\end{tabular}


Table 6: Flux Calibration Results - Indium Wire Measurements vs. MCNP Simulation

\begin{tabular}{|c|c|c|c|c|}
\hline Irradiation Spectrum & \multicolumn{3}{|c|}{$\begin{array}{c}\text { Thermal Flux Component } \\
\text { Measurement }\end{array}$} & \multicolumn{2}{c|}{$\begin{array}{c}\text { Fast Flux Component } \\
\text { MCNP Simulation }\end{array}$} & Measurement & MCNP Simulation \\
\hline \hline Fast-Neutron & $4.8 \mathrm{E}+5 \mathrm{n} / \mathrm{cm}^{2} / \mathrm{s}$ & $1.1 \mathrm{E}+6 \mathrm{n} / \mathrm{cm}^{2} / \mathrm{s}$ & $4.9 \mathrm{E}+8 \mathrm{n} / \mathrm{cm}^{2} / \mathrm{s}$ & $4.3 \mathrm{E}+8 \mathrm{n} / \mathrm{cm}^{2} / \mathrm{s}$ \\
\hline Thermal-Neutron & $1.0 \mathrm{E}+6 \mathrm{n} / \mathrm{cm}^{2} / \mathrm{s}$ & $3.0 \mathrm{E}+6 \mathrm{n} / \mathrm{cm}^{2} / \mathrm{s}$ & $7.3 \mathrm{E}+5 \mathrm{n} / \mathrm{cm}^{2} / \mathrm{s}$ & $4.3 \mathrm{E}+5 \mathrm{n} / \mathrm{cm}^{2} / \mathrm{s}$ \\
\hline Intermediate-Neutron & $2.1 \mathrm{E}+7 \mathrm{n} / \mathrm{cm}^{2} / \mathrm{s}$ & $2.5 \mathrm{E}+7 \mathrm{n} / \mathrm{cm}^{2} / \mathrm{s}$ & $2.5 \mathrm{E}+7 \mathrm{n} / \mathrm{cm}^{2} / \mathrm{s}$ & $4.8 \mathrm{E}+6 \mathrm{n} / \mathrm{cm}^{2} / \mathrm{s}$ \\
\hline
\end{tabular}


Table 7: Fast-Neutron Irradiation - Change in Intrinsic Remnant Induction

\begin{tabular}{|c|c|c|}
\hline \multirow{2}{*}{$\begin{array}{c}\text { Total Fast-Neutron Fluence } \\
\left(\mathrm{n} / \mathrm{cm}^{2}\right)\end{array}$} & \multicolumn{2}{|c|}{ Change in Intrinsic Remnant Induction } \\
\cline { 2 - 3 } & Irradiated Sample Magnets & Control Magnets \\
\hline \hline $9.86 \times 10^{5}$ & $0.321 \%$ & $0.228 \%$ \\
$9.88 \times 10^{7}$ & $0.104 \%$ & $0.042 \%$ \\
$9.99 \times 10^{9}$ & $0.125 \%$ & $0.062 \%$ \\
$1.09 \times 10^{12}$ & $0.031 \%$ & $0.083 \%$ \\
$1.83 \times 10^{12}$ & $0.094 \%$ & $0.146 \%$ \\
$2.33 \times 10^{13}$ & $0.590 \%$ & $0.000 \%$ \\
$4.07 \times 10^{13}$ & $0.761 \%$ & $0.021 \%$ \\
$1.61 \times 10^{14}$ & $16.172 \%$ & $0.042 \%$ \\
\hline
\end{tabular}


Table 8: Thermal-Neutron Irradiation - Change in Intrinsic Remnant Induction

\begin{tabular}{|c|c|c|}
\hline Total Thermal-Neutron Fluence & \multicolumn{2}{|c|}{ Change in Intrinsic Remnant Induction } \\
\cline { 2 - 3 }$\left(\mathrm{n} / \mathrm{cm}^{2}\right)$ & Irradiated Sample Magnets & Control Magnet \\
\hline \hline $1.10 \times 10^{6}$ & $0.000 \%$ & $0.041 \%$ \\
$3.53 \times 10^{7}$ & $0.000 \%$ & $0.041 \%$ \\
$6.14 \times 10^{8}$ & $0.041 \%$ & $0.041 \%$ \\
$1.50 \times 10^{9}$ & $0.000 \%$ & $0.041 \%$ \\
$8.41 \times 10^{9}$ & $0.062 \%$ & $0.000 \%$ \\
$2.68 \times 10^{10}$ & $0.062 \%$ & $0.000 \%$ \\
$9.12 \times 10^{10}$ & $0.021 \%$ & $0.041 \%$ \\
$1.08 \times 10^{11}$ & $0.021 \%$ & $0.000 \%$ \\
$4.88 \times 10^{11}$ & $0.000 \%$ & $0.082 \%$ \\
$9.99 \times 10^{11}$ & $0.083 \%$ & $0.082 \%$ \\
$1.52 \times 10^{12}$ & $0.062 \%$ & $0.082 \%$ \\
$2.94 \times 10^{12}$ & $0.021 \%$ & $0.082 \%$ \\
$3.34 \times 10^{12}$ & $0.000 \%$ & $0.000 \%$ \\
\hline
\end{tabular}




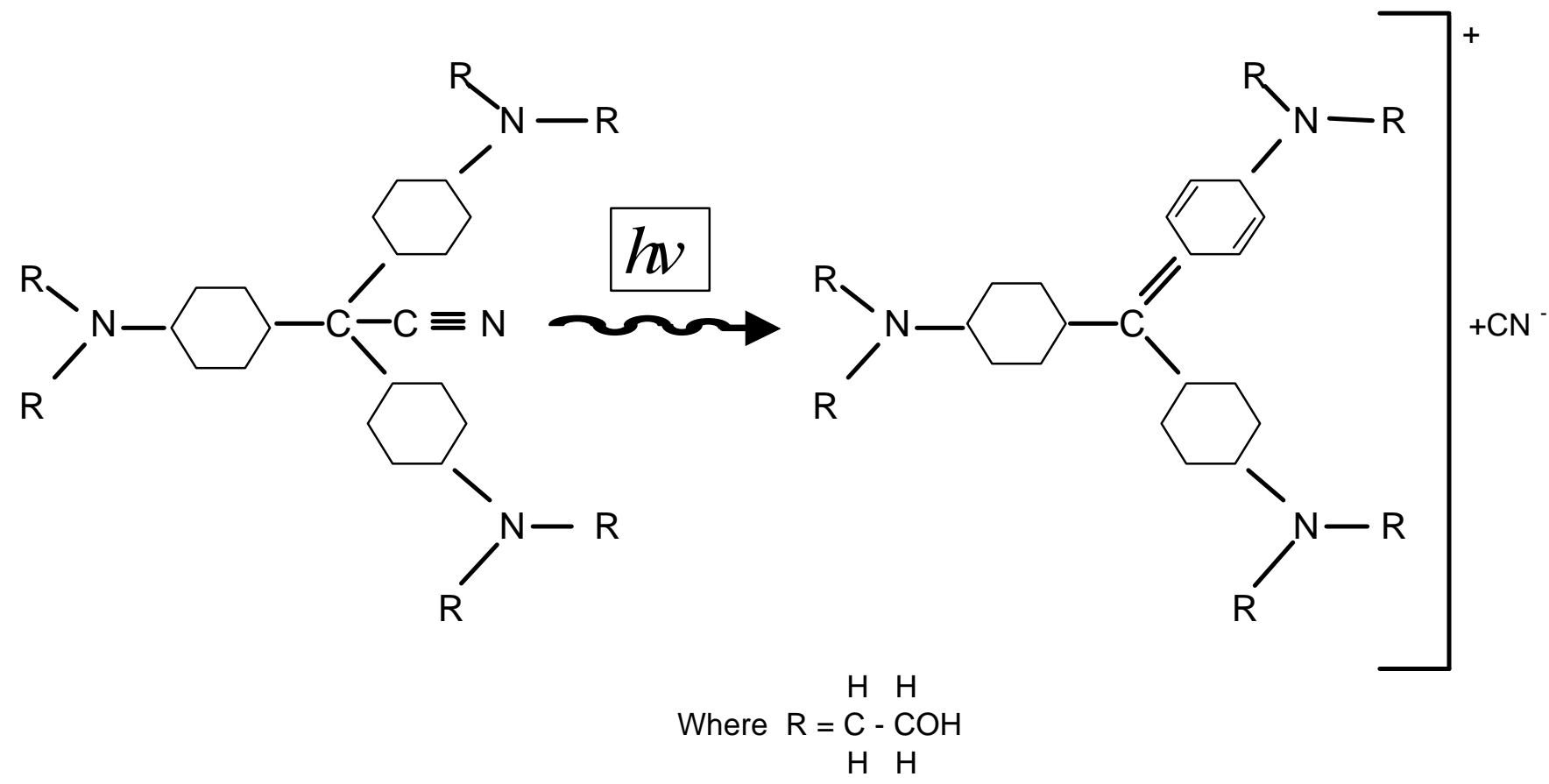

Figure 1: Radiation-Induced Photochemical Reaction in Radiachromic Films 


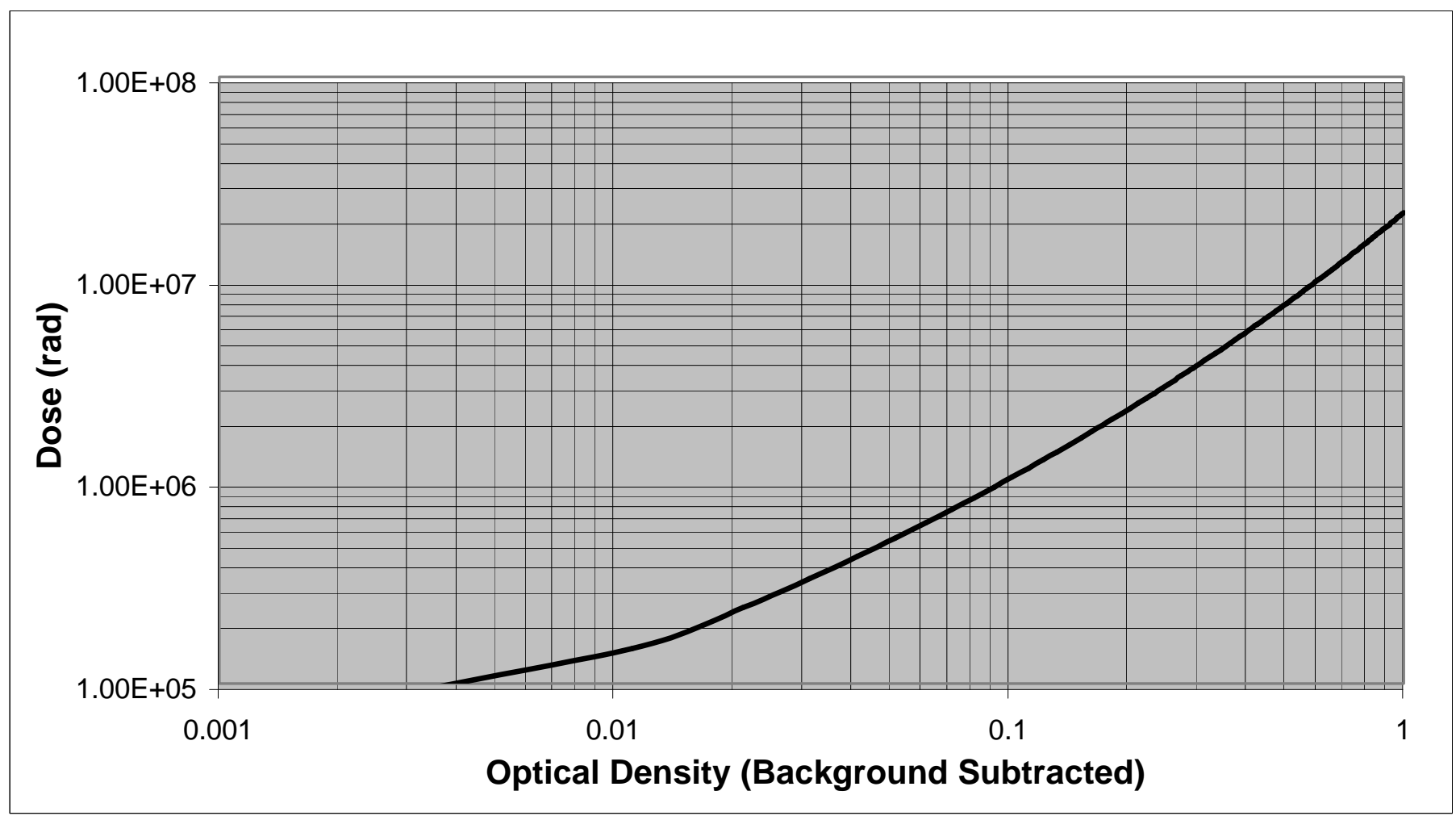

Figure 2: Calibration Curve for FWT-60 Radiachromic Films 


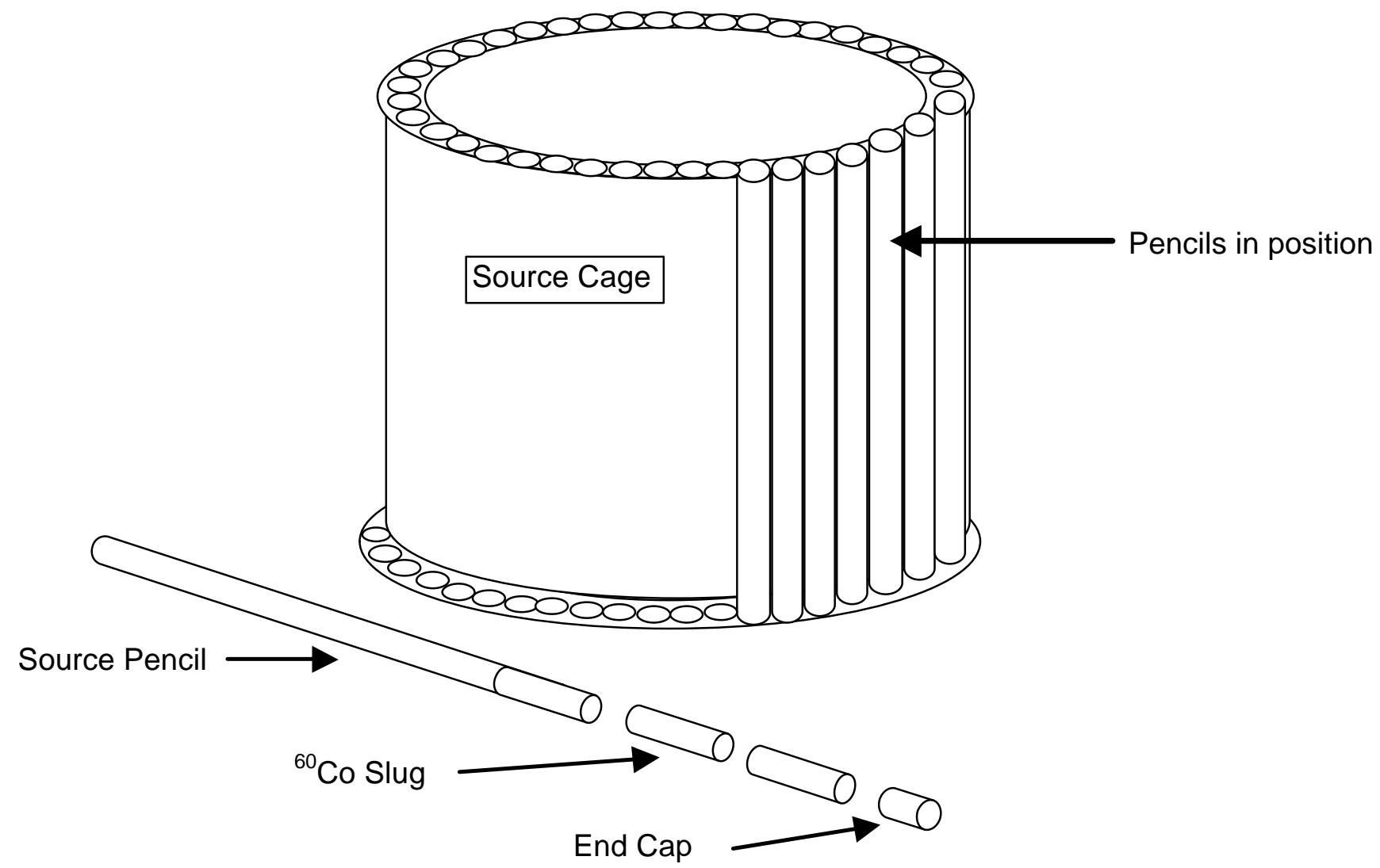

Figure 3: Source Cage and "Pencil" Source Arrangement for Gamma Irradiation 


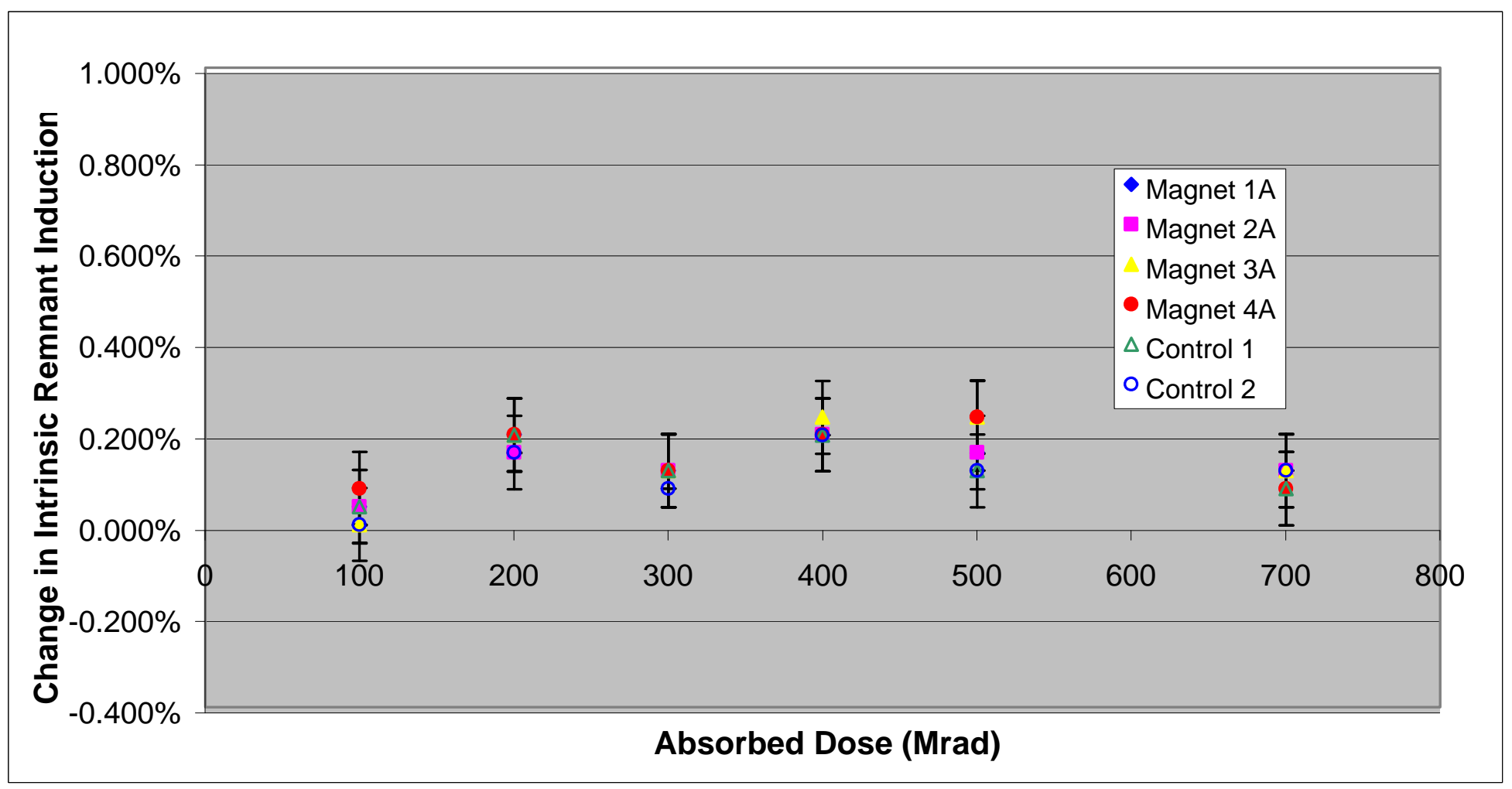

Figure 4: Change in Intrinsic Remnant Induction from ${ }^{60} \mathrm{Co}$ Gamma Irradiation 


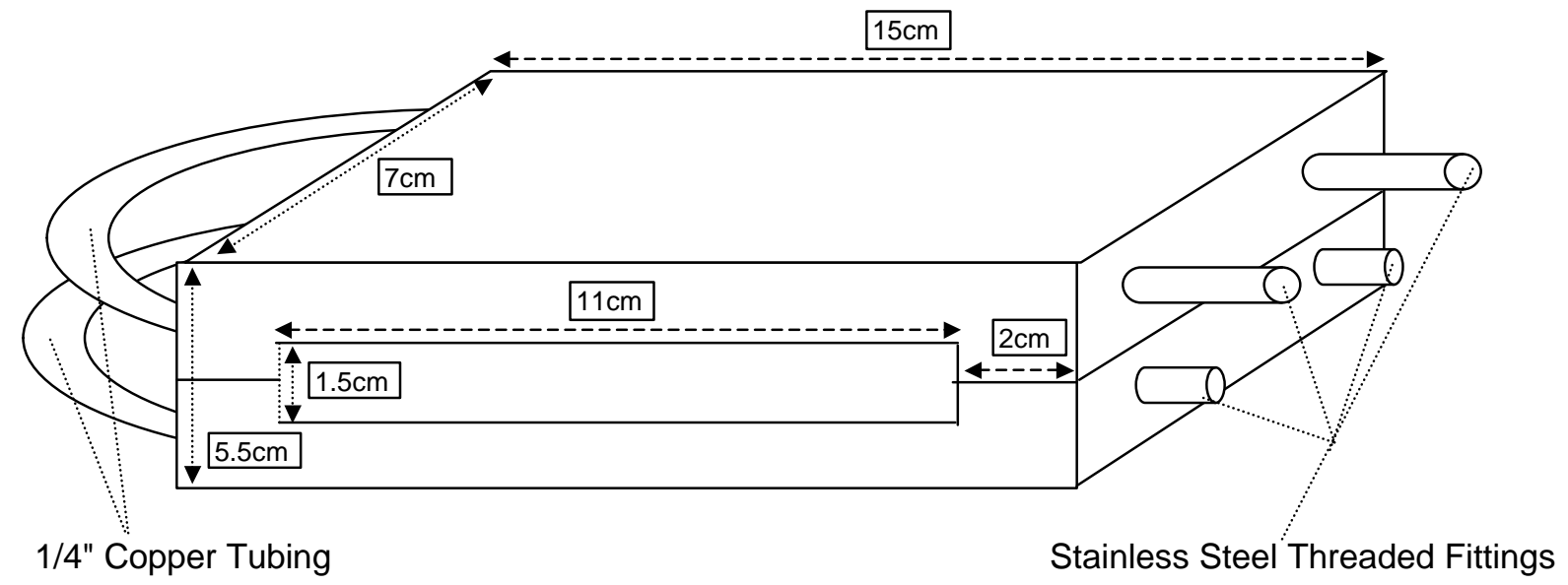

Figure 5: Steel Magnet Holder with Copper Cooling Tubes 


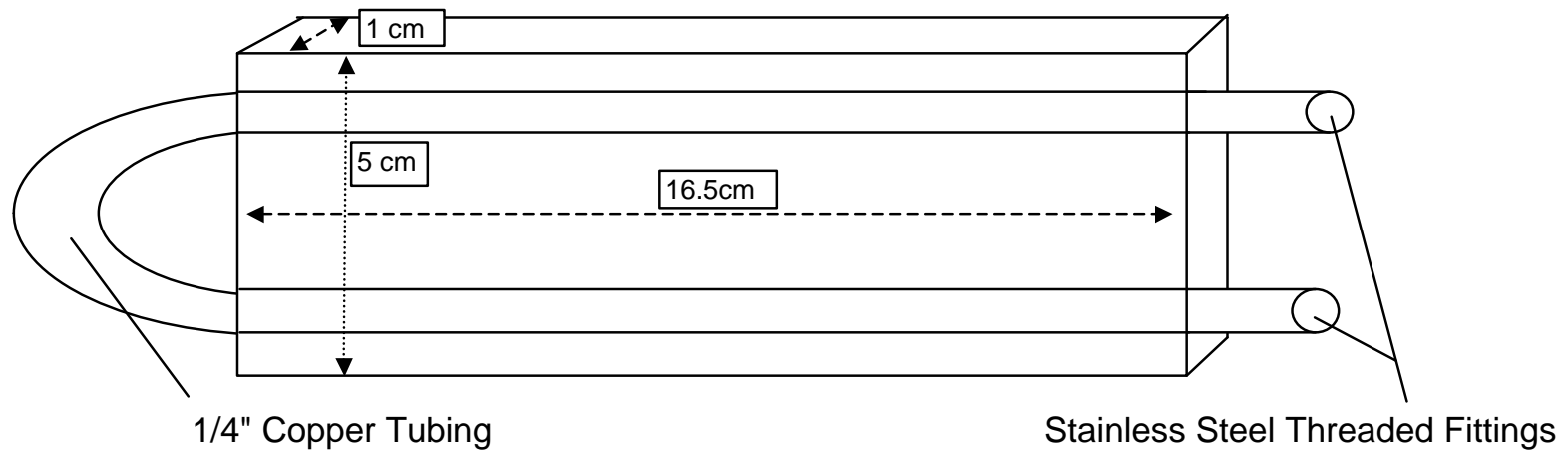

Figure 6: Aluminum Spreader with Copper Cooling Tubes 


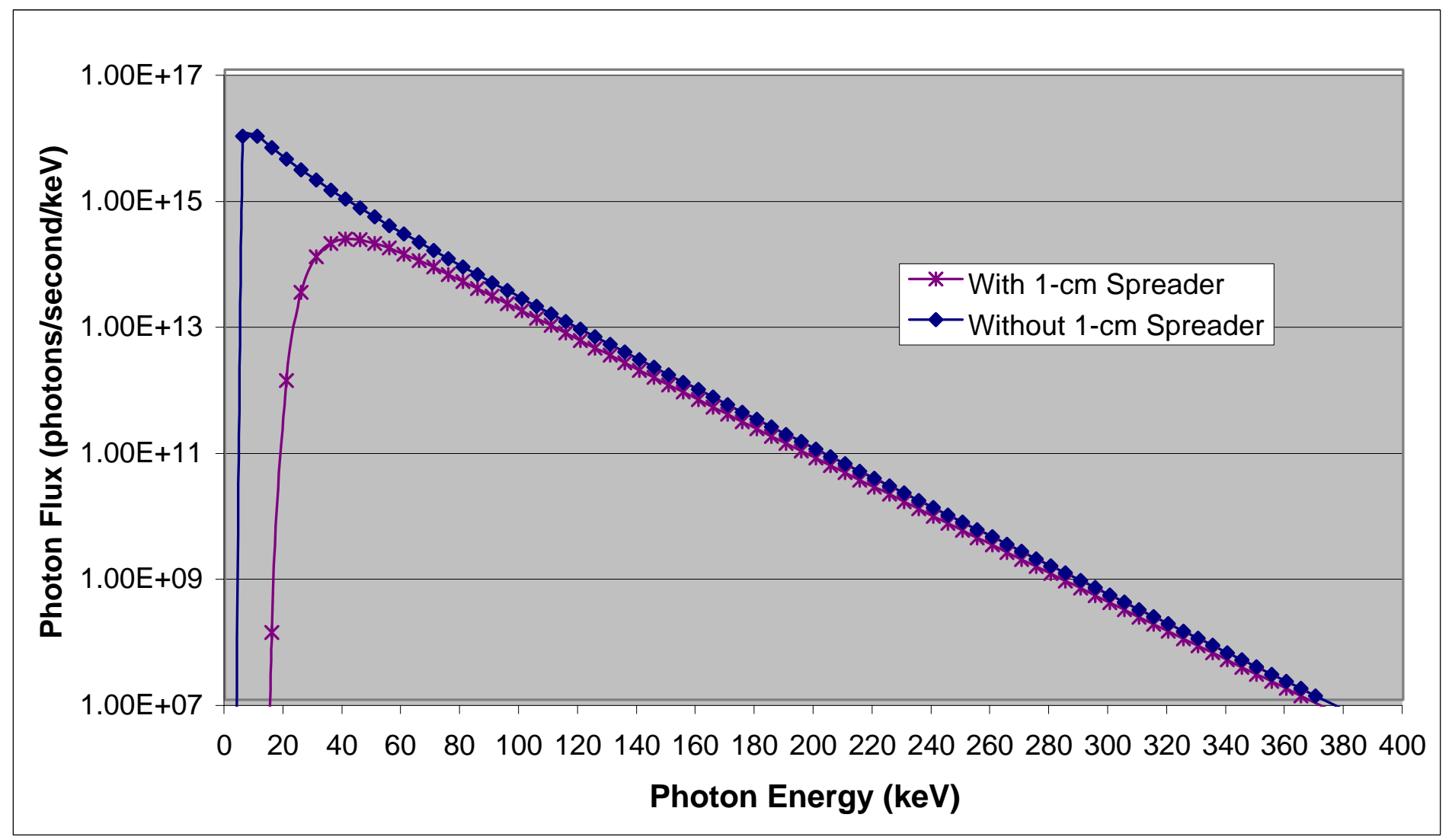

Figure 7: Calculated Bending Magnet Irradiation Spectrum for APS Beamline 9 BM Results of PHOTON Simulation 


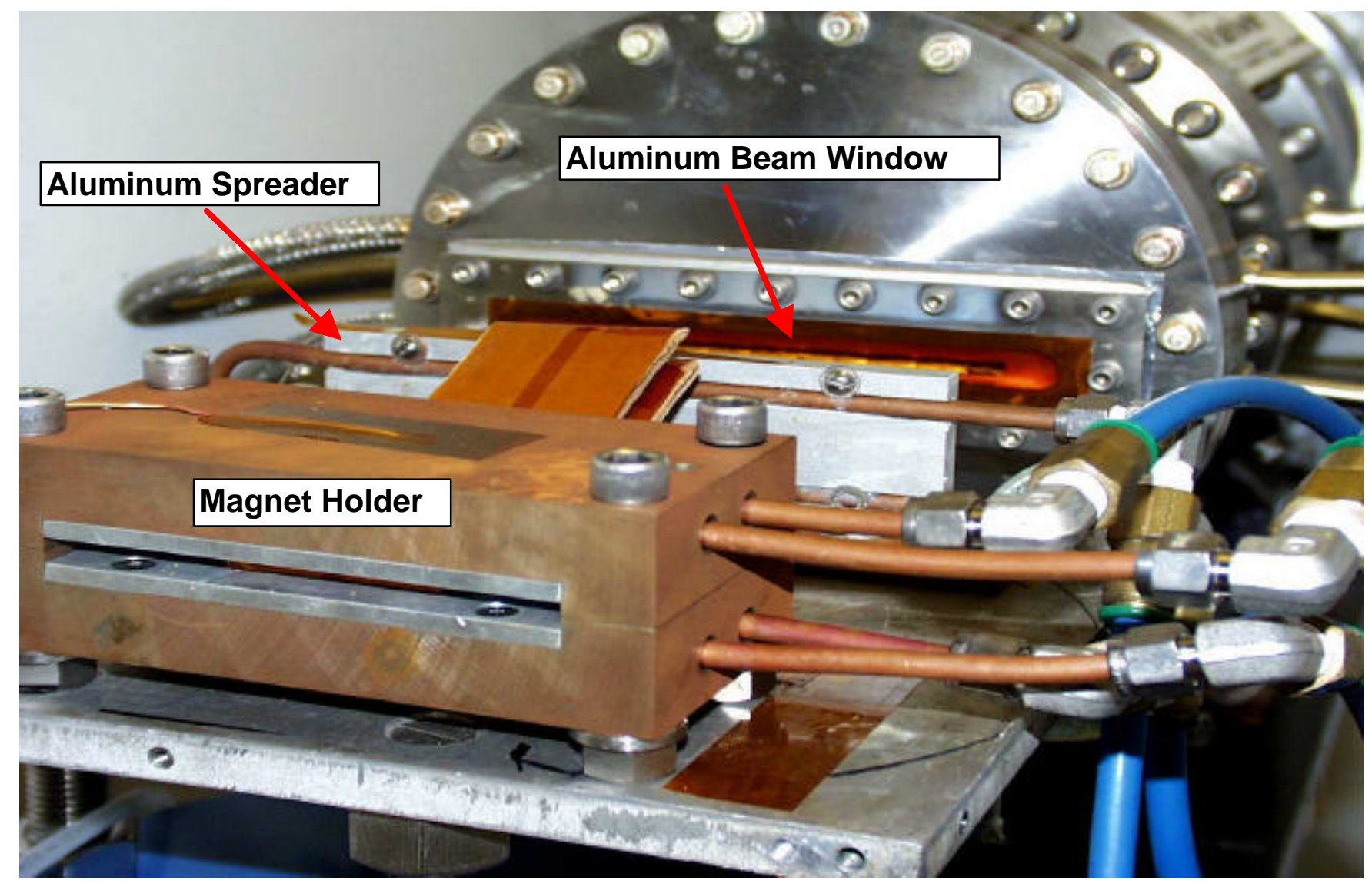

Figure 8: X-ray Irradiation Configuration Photograph 


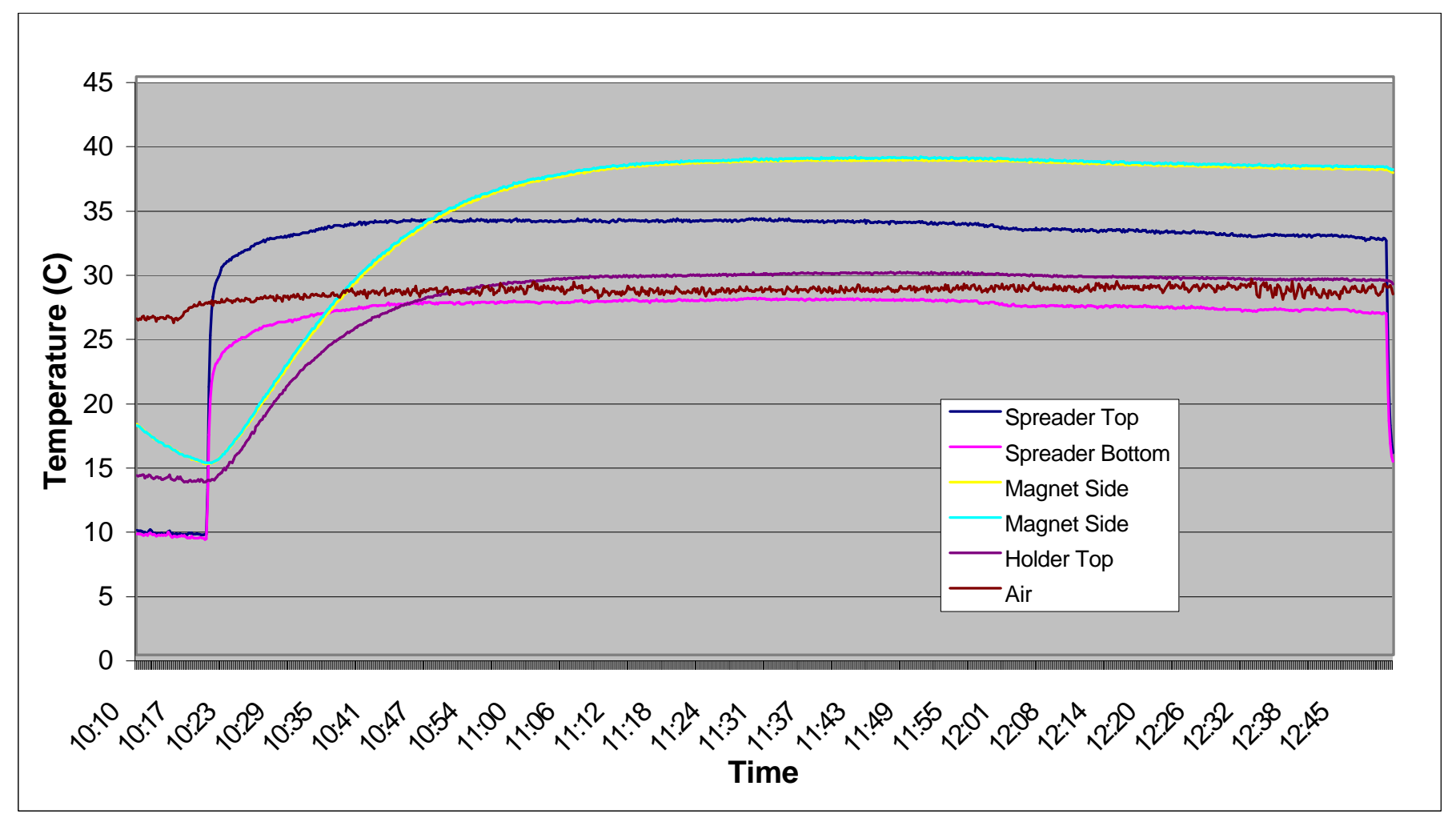

Figure 9: Typical Temperature Stabilization Plot During Irradiation with APS Bending Magnet X-rays 


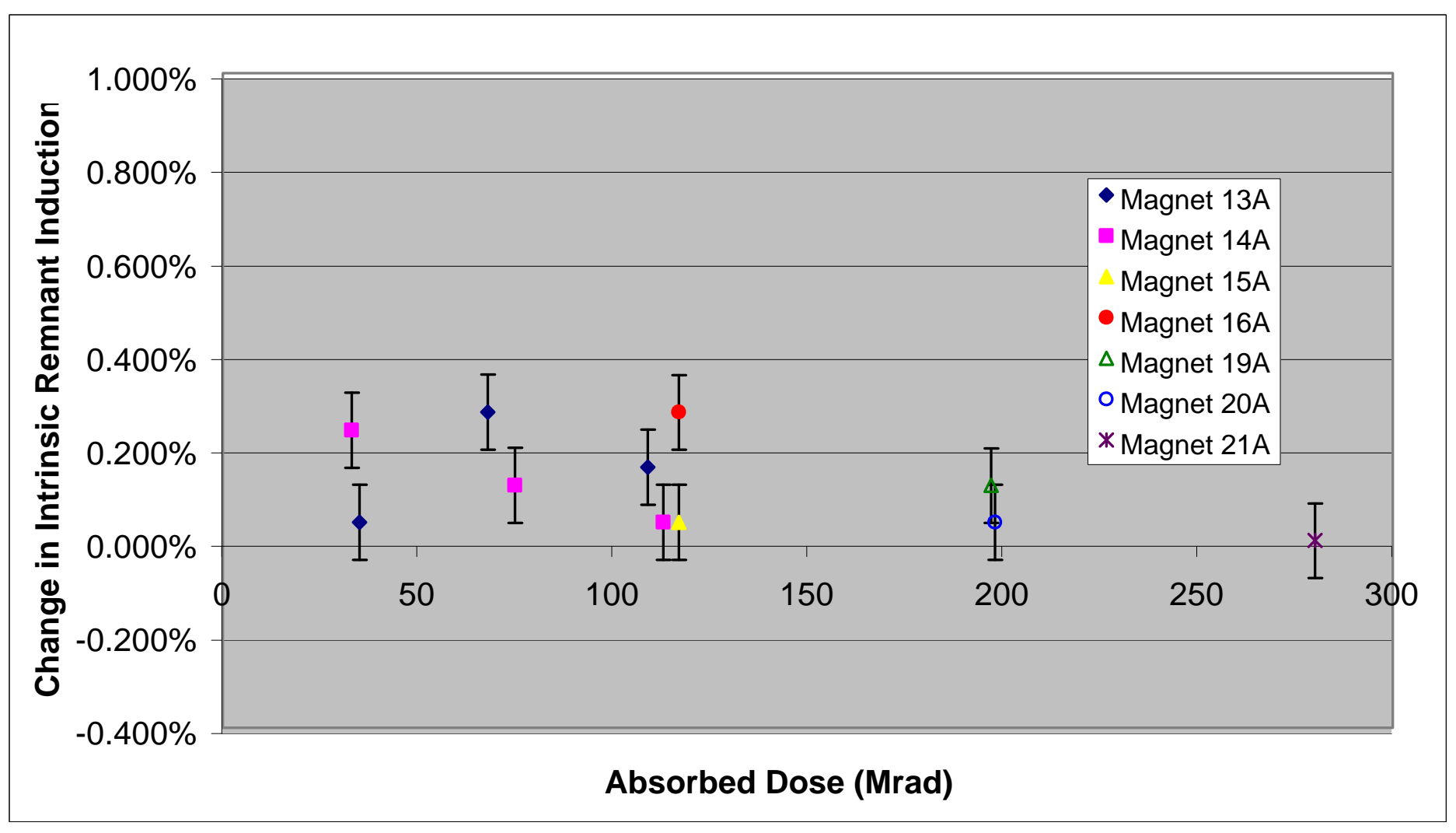

Figure 10: Change in Intrinsic Remnant Induction from APS Bending Magnet X-ray Irradiation 


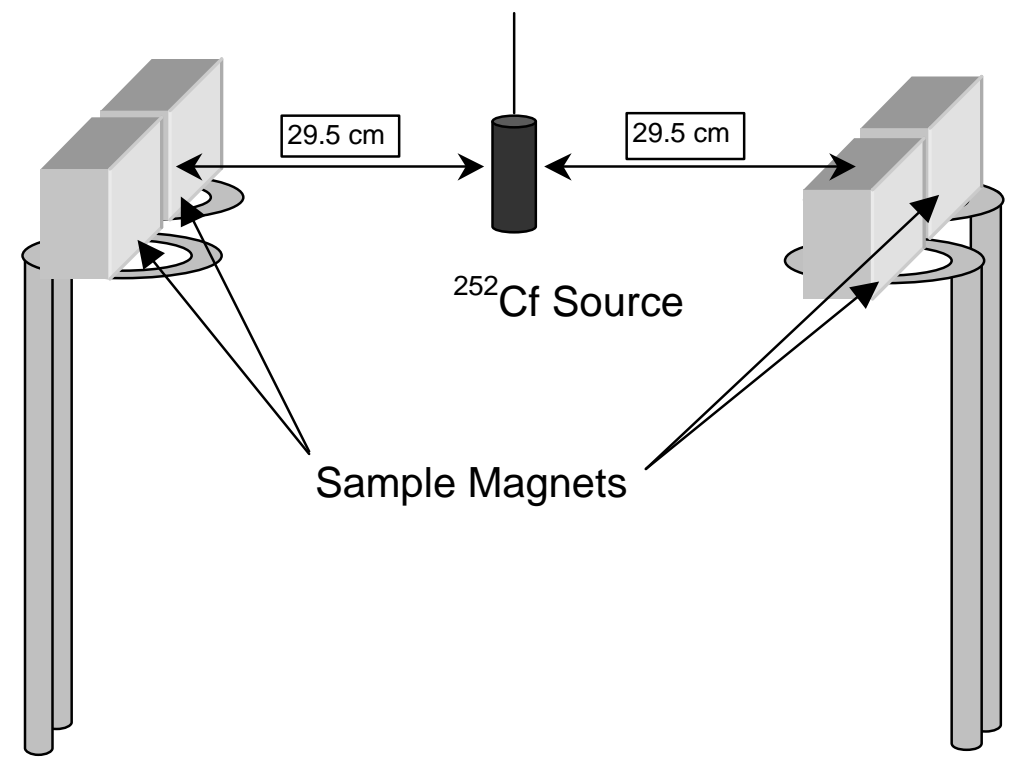

Figure 11: Schematic Diagram of Fast-Neutron Irradiation Configuration 


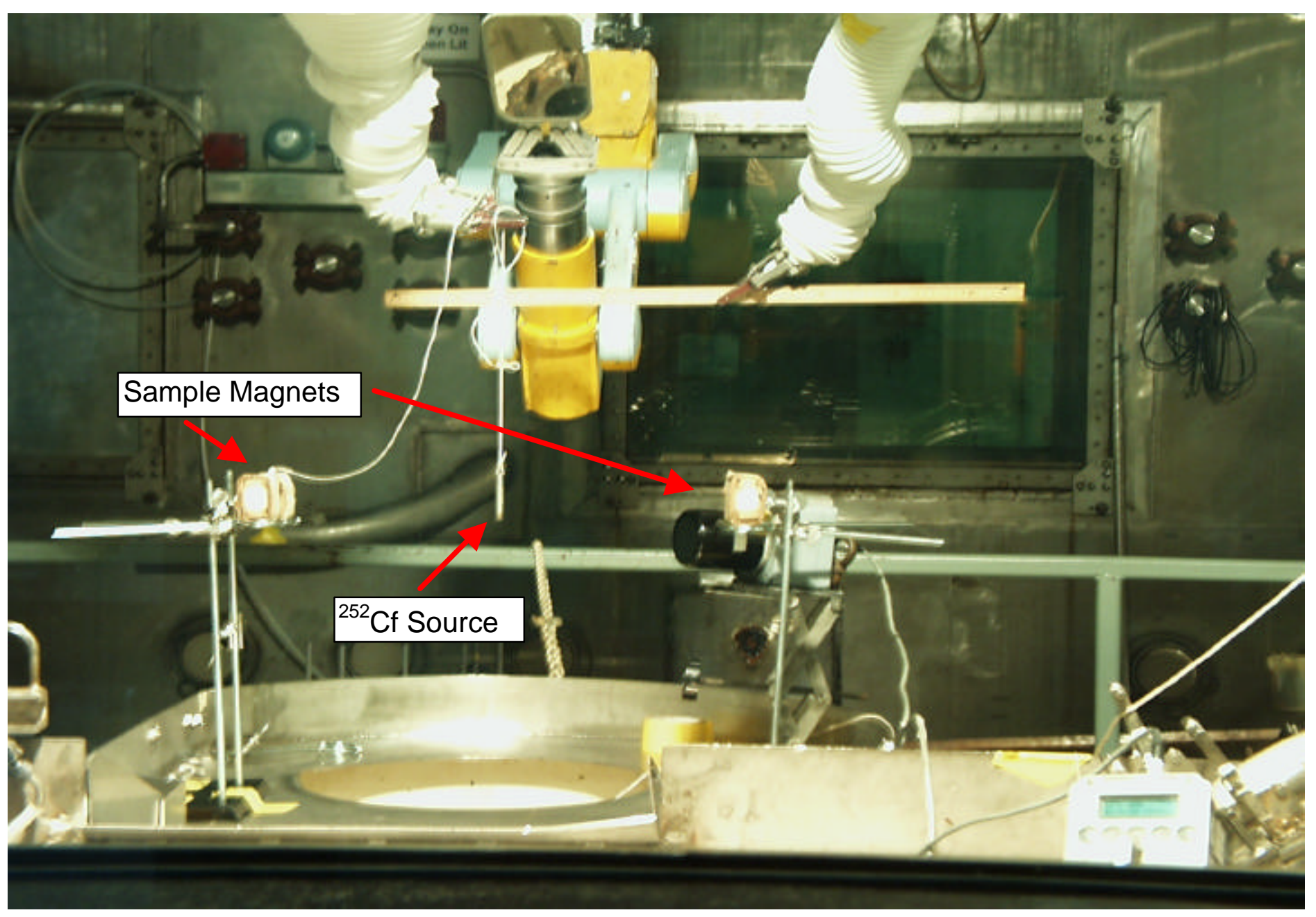

Figure 12: Photograph of Fast-Neutron Irradiation Configuration Inside Hot Cell 


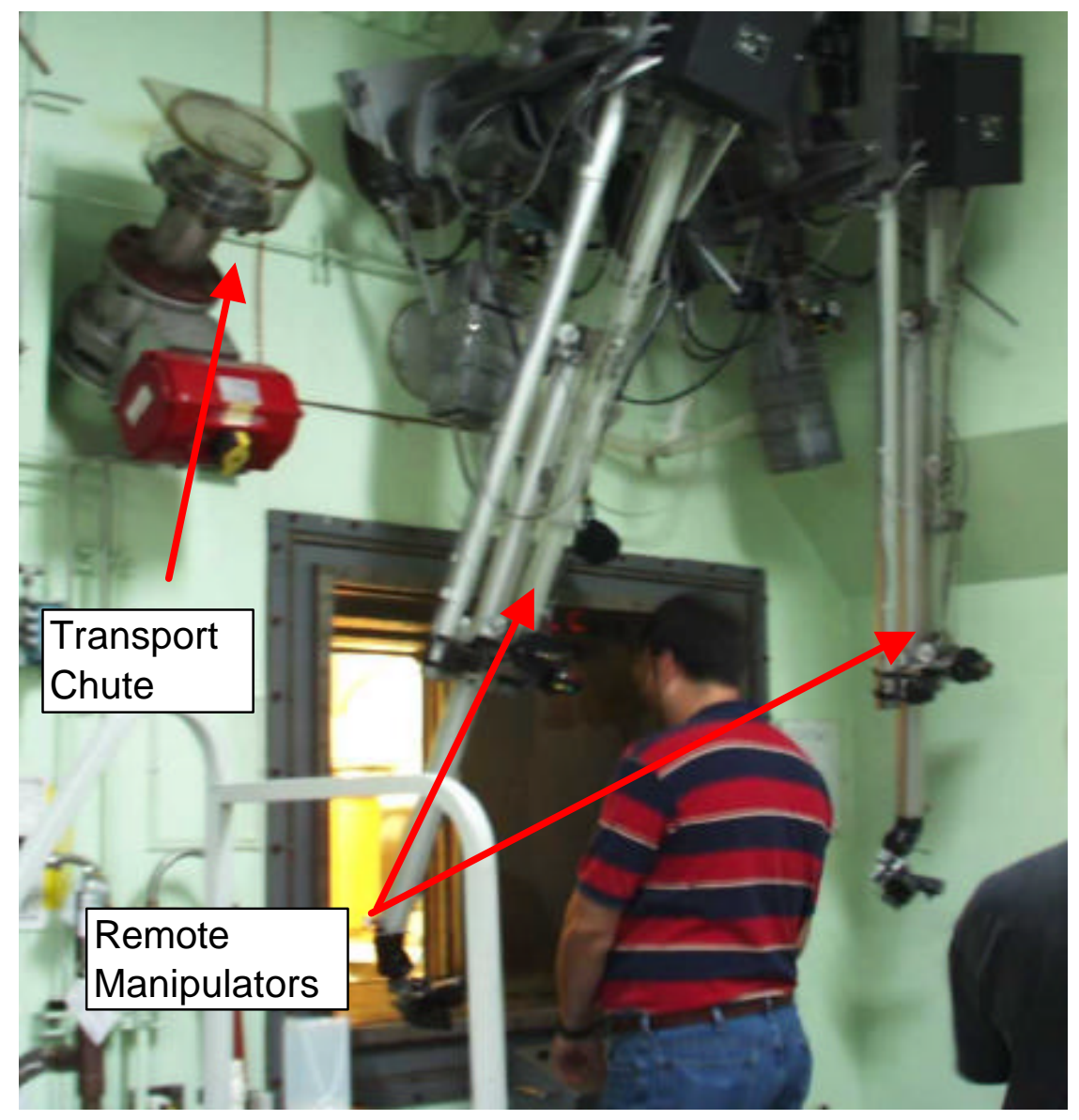

Figure 13: Photograph of Transport Chute and Remote Manipulators 


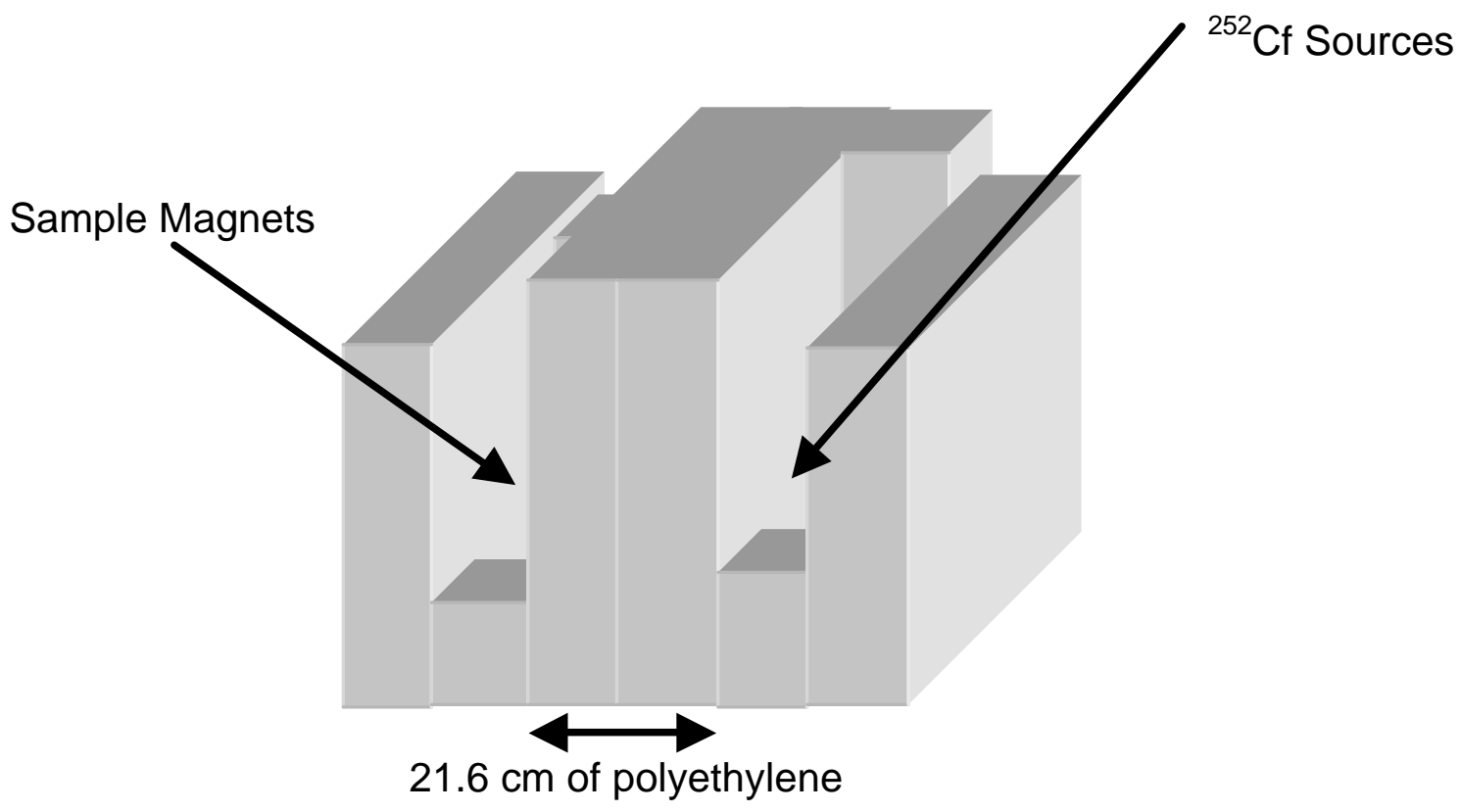

Figure 14: Schematic Diagram of Thermal-Neutron Irradiation Configuration 


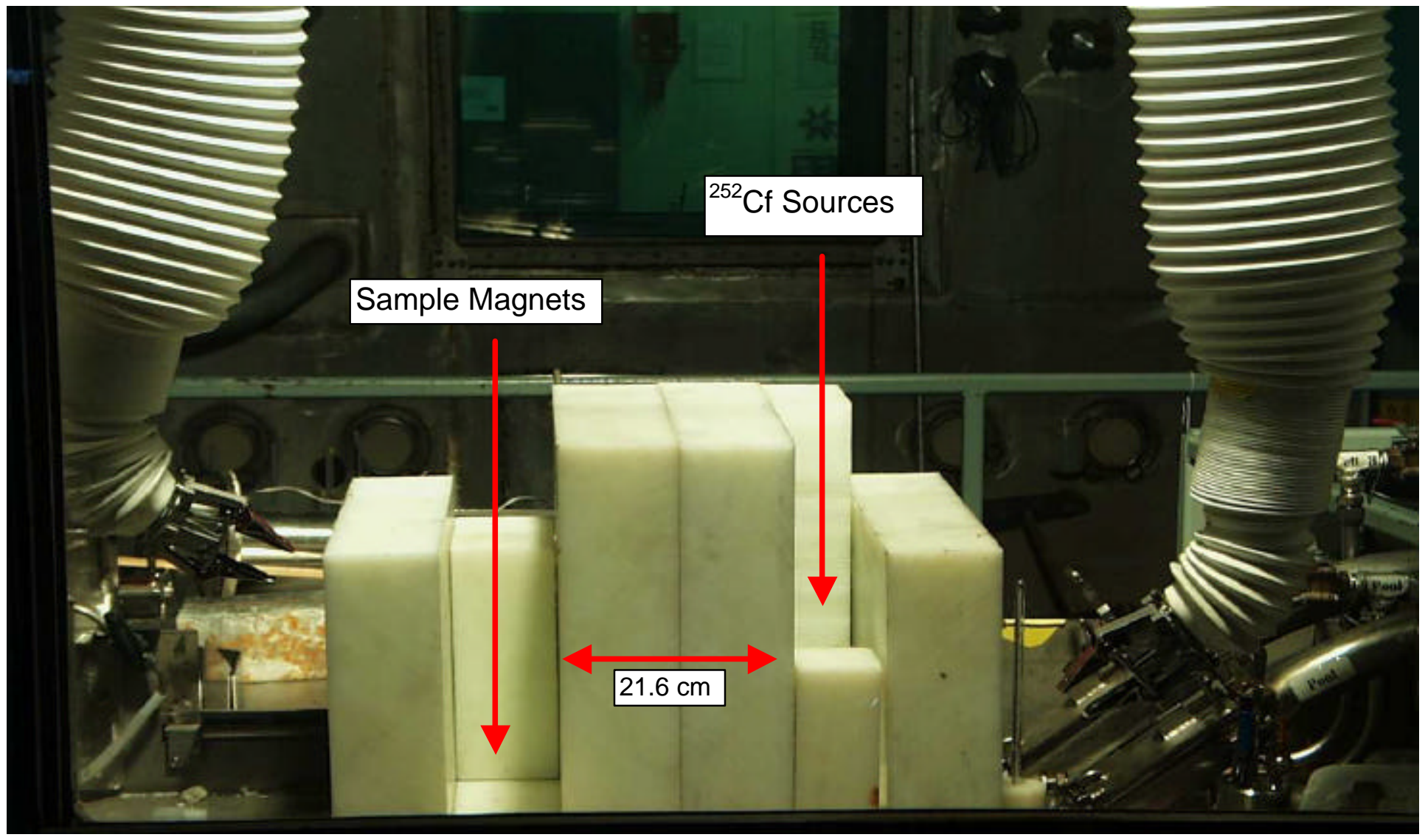

Figure 15: Photograph of Thermal-Neutron Irradiation Configuration Inside Hot Cell 


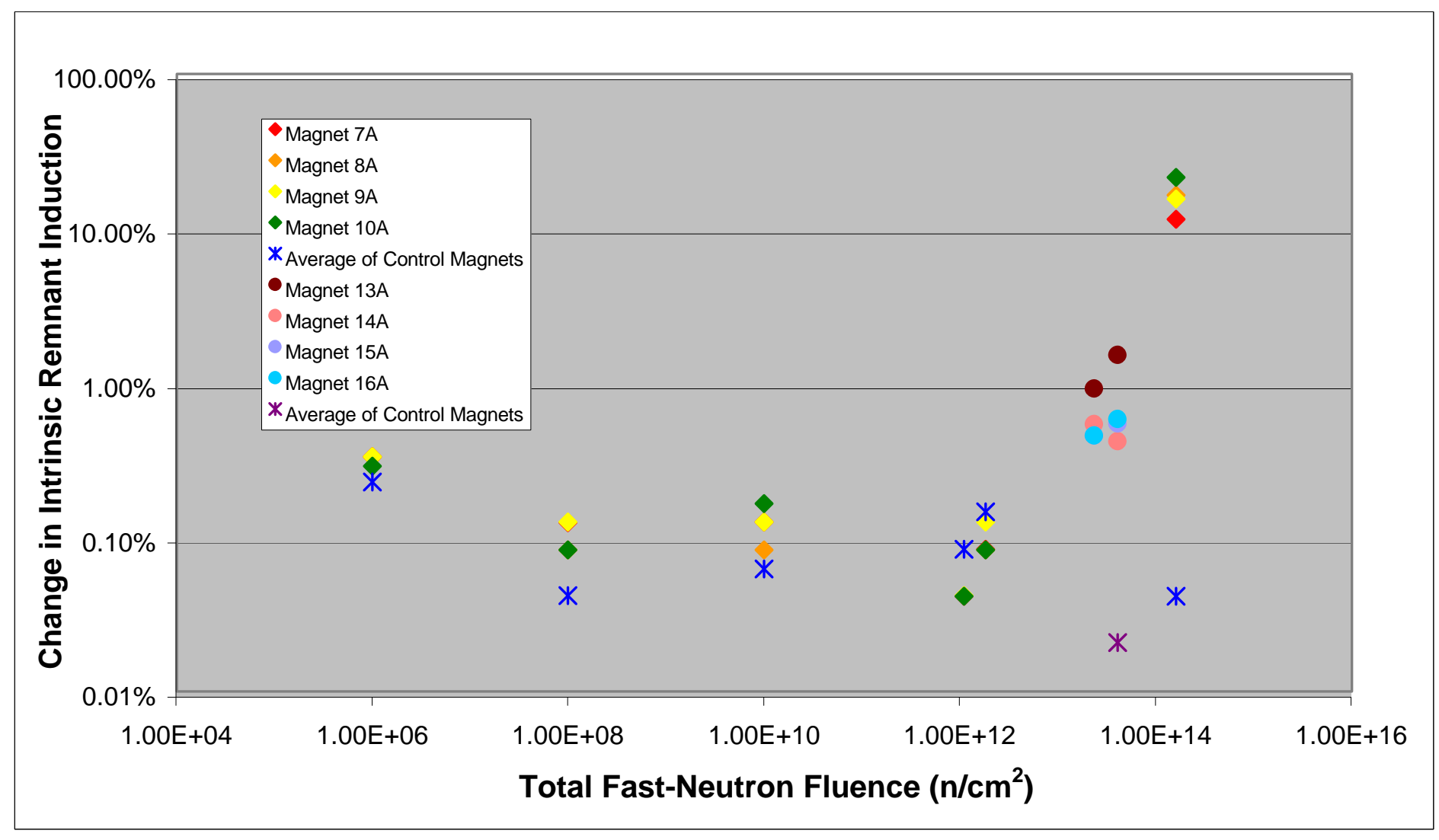

Figure 16: Change in Intrinsic Remnant Induction from Fast-Neutron Irradiation in ${ }^{252} \mathrm{Cf}$ Spectrum 


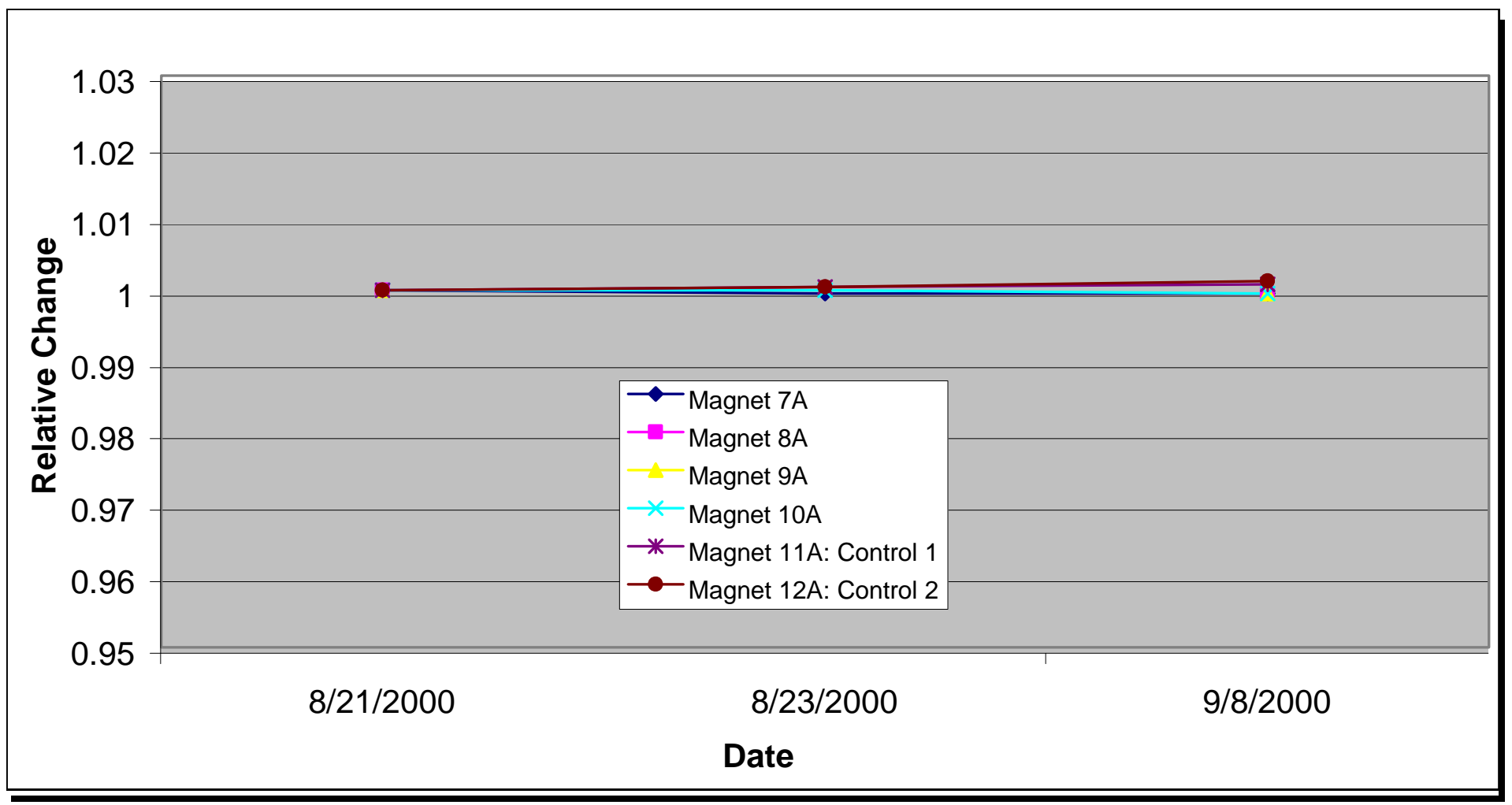

Figure 17: Relative Change in Intrinsic Remnant Induction with Annealing Effects 


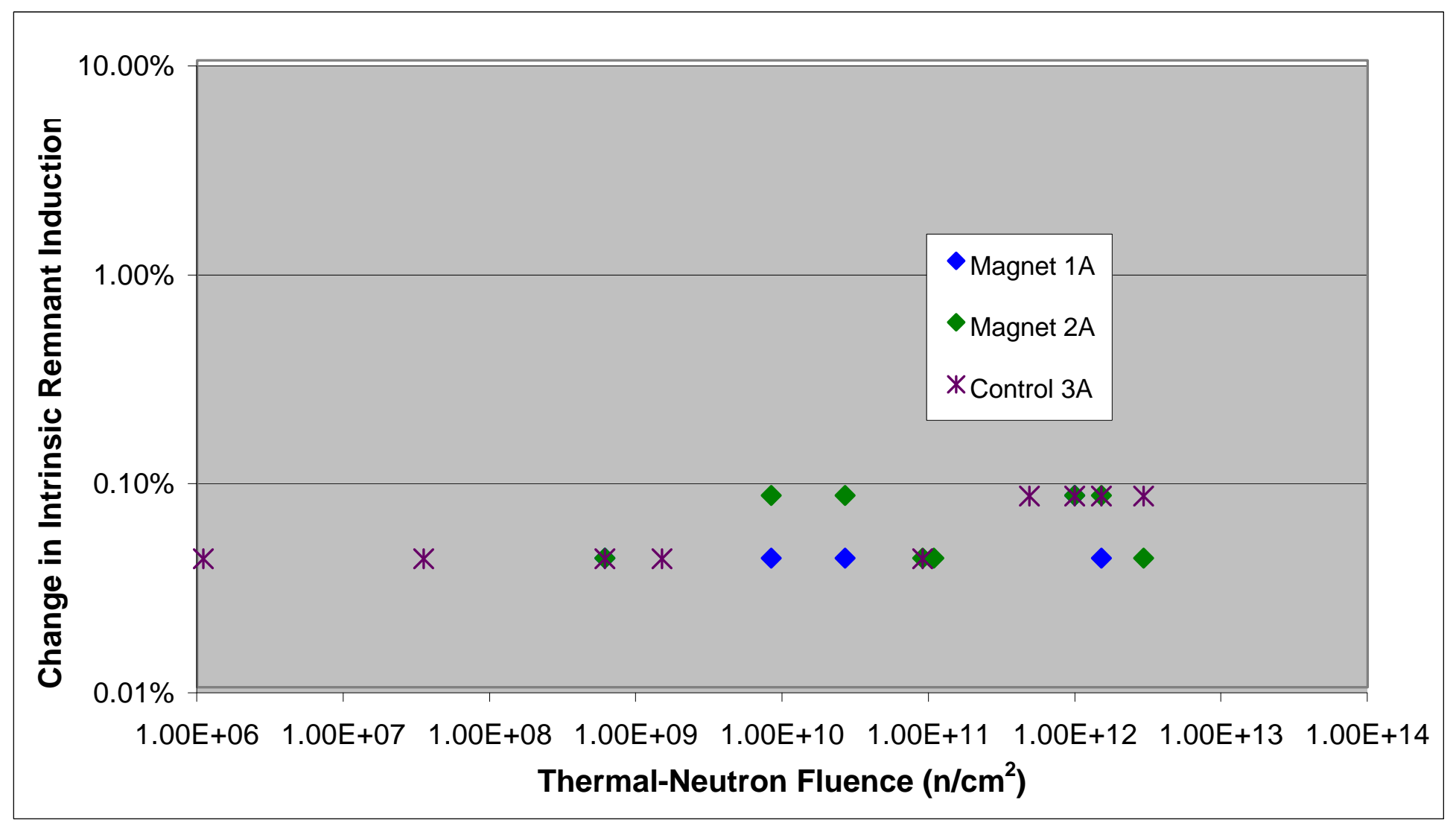

Figure 18: Change in Intrinsic Remnant Induction from Thermal-Neutron Irradiation in ${ }^{252} \mathrm{Cf}$ Spectrum 